\title{
Technological Growth and Hours in the Long Run: Theory and Evidence
}

\author{
By Magnus ReiF*, Mewael F. Tesfaselassie† and Maik H. Wolters $\$$ \\ *Deutsche Bundesbank, CESifo, ifo Institute $\quad \dagger$ University of Mannheim $\quad \ddagger$ University of \\ Wuerzburg, Kiel Institute for the World Economy, ifo Institute
}

Final version received 15 June 2021.

\begin{abstract}
Over the last few decades, hours worked per capita have declined substantially in many OECD economies. Using the standard neoclassical growth model with endogenous work-leisure choice, we assess the role of trend growth slowdown in accounting for the decline in hours worked. In the model, a permanent reduction in technological growth decreases steady-state hours worked by increasing the consumptionoutput ratio. Our empirical analysis exploits cross-country variation in the timing and size of the decline in technological growth to show that technological growth has a highly significant positive effect on hours. A decline in the long-run trend of technological growth by 1 percentage point is associated with a decline in trend hours worked in the range of $1-3 \%$. This result is robust to controlling for taxes, which have been found in previous studies to be an important determinant of hours. Our empirical finding is quantitatively in line with the one implied by a calibrated version of the model, though evidence for the model's implication that the effect on hours works via changes in the consumption-output ratio is rather mixed.
\end{abstract}

\section{INTRODUCTION}

The effects of technology shocks for the short-run dynamics of hours worked have been analysed extensively in the business cycle literature (see, for example, Galí (1999) among many others). By contrast, the link between the long-run trends of technological growth and hours has not yet received much attention. This is surprising, because the data suggest that there is a potential link between trend changes of the two variables. For instance, during the postwar period, industrialized countries experienced a long-term trend decline in both productivity growth and the average number of hours worked per person (see, for example, OECD 1998; Ohanian et al. 2008; Gordon 2016). Long-run changes in hours worked exceed cyclical fluctuations by roughly an order of magnitude across OECD countries, as shown by Ohanian et al. (2008). Hence analysing sources of long-run changes in hours is even more important than hour dynamics over the business cycle. $^{1}$

Several alternative explanations for trends in hours over time, as well as for differences in hours worked across countries, have been proposed in the literature, including tax rates (e.g. Prescott 2004; Ohanian et al. 2008; McDaniel 2011; Bick and Fuchs-Schündeln 2018), institutions (Alesina et al. 2005), social security systems (Erosa et al. 2012; Wallenius 2013; Alonso-Ortiz 2014), and non-standard preferences in which the income effect of wages slightly outweighs the substitution effect (Boppart and Krusell 2020). Our theoretical and empirical results suggest that technological growth is also an important factor in explaining trends in hours worked.

We use the standard neoclassical growth model with exogenous technological change to derive theoretical implications regarding the link between technological growth and hours worked. The model features a stand-in household that faces a work-leisure decision and a consumption-investment decision. Production technology and household preferences are specified in line with balanced growth facts (King et al. 1988). The model is relatively simple and has an analytical solution. 
In the model, productivity growth affects steady-state hours through the steady-state consumption-output ratio. From the standard condition for the optimal labour supply, hours worked is decreasing in the consumption-output ratio. What we show is that the lower productivity growth, the higher the steady-state consumption-output ratio and thus the lower steady-state hours worked. Quantitatively, the model's prediction is quite sensitive to particulars of the calibration. For instance, for the range of plausible values for the elasticity of substitution between capital and labour, the model implies that a one percentage point decrease in productivity growth leads to a decrease in steady state hours worked in the range from $0.35 \%$ to $3.4 \%$.

Importantly, our focus on permanent change in productivity growth is distinct from the standard analysis of the effect of permanent changes in the level of technology. With balanced growth restrictions, a change in the level of technology does not affect steadystate hours, as the substitution and income effects on labour supply cancel out. By contrast, a change in the growth rate of technology affects steady-state hours as a result of changes in the optimal mix of labour and capital. Our analysis is also distinct from the negative correlation between the long-run rate of productivity growth and the long-run growth rate in hours studied by Boppart and Krusell (2020). While they propose a new preference class that can explain this link, we use standard preferences, so that the modelimplied correlation between the long-run productivity growth rate and the long-run growth rate of hours is zero.

In our empirical analysis, we ascertain whether the theoretical predictions derived from the standard model can be validated empirically. To this end, we use data for 15 OECD countries and extract the low-frequency components of different measures of technological growth and hours worked by Hodrick-Prescott (HP) filtering the data with different smoothing parameters and by computing decade averages. We employ panel estimates to study the link between the long-run trend of technological growth and hours. Our identification comes from cross-country differences in the extent and the timing of the growth slowdown. While the long-run trends of total factor productivity (TFP) and labour productivity growth have declined almost monotonically in a number of European countries and in Japan from the 1960s onwards, other countries-for example, the USA, Canada, and Australia-have recorded an acceleration of technological growth from the mid-1980s to the early 2000s after the declines in the 1960s and 1970s. Similarly, the changes in the long-run trend in hours show large differences across countries, ranging from declines of more than 30\% in Germany and France from the 1960s onwards, to small increases in the USA and Australia.

Controlling for cross-sectional and time fixed effects, we find that a one percentage point decrease in trend technological growth leads to a decrease in the trend of hours worked in the range of $1-3 \%$, depending on the specific technology measure, the trend extraction method, the sample studied, and the treatment of outliers. The effect is highly significant. The empirical results are in line with the size of the link between technological growth and hours predicted by the model.

Previous studies found that, in particular, changes in taxes are a major determinant of changes in hours over time. One might argue that taxes can affect long-run technological growth and therefore it could be that taxes are at least to some extent the driving force behind the observed link between long-run technological growth and longrun hours. However, our reading of the literature is that while the empirical evidence on taxes and labour supply is robust, the empirical evidence on the relationship between taxes and long-run economic growth is as yet inconclusive (see, for example, Gale and Samwick 2017). Nevertheless, we construct effective tax rates as in McDaniel (2006) and 
enter these as controls in the regressions of hours on technological growth. We find that even when controlling for taxes, there is still a highly significant and sizeable effect of technological growth on hours. Hence changes in the long-run trend of technological growth are an important independent driver of the long-run trend in hours. Our estimates also confirm the finding from previous studies that the effective labour income tax has a highly significant impact on hours.

Finally, we investigate whether the empirical findings can be reconciled with the mechanism of the standard model. In the model, trend technological growth has a negative effect on the trend consumption-output ratio, which in turn affects trend hours negatively. In the data, these correlations are negative for 11 out of 15 countries in our sample. For these 11 countries, we also inspect the model's mechanism quantitatively. We focus on the households' intratemporal first-order condition that governs the time allocation decision, and check to which extent this condition holds at each point in time in the data. A similar exercise is conducted by Prescott (2004) and Ohanian et al. (2008) but focusing on hours at business cycle frequency. We use the calibrated neoclassical growth model and observable tax wedge and consumption-output ratio data to predict hours for the period 1957-2004. For this, we use effective tax rates as constructed in McDaniel (2006). We confirm the results from Prescott (2004) and Ohanian et al. (2008) that variations in the tax wedge are important for explaining the dynamics of hours. Importantly, we find that consumption-output variations are an important determinant of the dynamics of hours worked that are not explained by the tax channel. Overall, we conclude that the evidence for the model mechanism is mixed, because for 4 out of 15 countries the correlations have the wrong sign, and even for the other 11 countries the tax effect on hours dominates, and the effect via the consumption-output ratio plays only a secondary role, because variations in the consumption-output ratio are empirically rather small. Hence the model mechanism cannot fully explain the effect of trend technological growth on trend hours that we find empirically, so there might be additional channels through which technological growth affects hours in the long run that are not included in the standard neoclassical growth model.

There are few related papers studying the link between growth and hours; the focus on the long-run relation between technological growth and hours in our paper is new.

Rogerson (2006) focuses on technology and government (in terms of tax receipts to GDP) as driving forces for the evolution of hours worked, and suggests that combining both forces is essential. This study substantially differs from ours in two key aspects. First, regarding the effect of technology, he focuses on a catch-up effect relative to a country at the technological frontier. Second, he does not provide a quantitative modelbased or empirical evaluation of the suggested channels.

McDaniel (2011) focuses on changes in labour tax rates to explain the development of hours for 15 OECD countries, but also considers productivity growth as a driving force. Her approach is fundamentally different from ours in three respects, though. First, similar to Rogerson (2006), she focuses on growth catch-up relative to the USA. We assume instead that the economies studied are on a balanced growth path, and we study changes in steady-state productivity growth rates. Hence the effects of productivity growth on hours work via different channels. Second, we abstract from home production and subsistence consumption as for most countries the inclusion of home production causes some challenges. There are no data to construct productivity growth in home production, and McDaniel (2011) shows that the predictions of a simpler model without home production are, on average across countries, closer to the data. We show that when focusing on steady-state comparisons, the simple model can indeed explain actual hours 
worked quite well. Third, the analysis of McDaniel (2011) is purely model-based, while we also study panel estimates. Our model-based analysis confirms that productivity growth plays only a secondary role after taxes for explaining hours. The empirical analysis shows instead that both are similarly important. This is quite interesting, in particular, as McDaniel (2011) shows that the tax wedges predict for most countries a much larger decline in hours than actually occurred. Hence, the focus on taxes in the literature might stem from the large effects of these in model-based analyses, while our panel estimates show that this might not be fully empirically justified.

Another paper related to ours is the one by Ngai and Pissarides (2008). They build a model of uneven TFP growth in market and home production that leads to long-run changes in market hours. The TFP growth rates in market and home production differ from each other, but they are constant over time, while we study changes in the trend growth rate of TFP.

Furthermore, there exists a related but distinct literature that examines the effect of long-run technological change on steady-state unemployment (e.g. Pissarides 2000; Aghion and Howitt 1994; Eriksson 1997; Tesfaselassie and Wolters 2018).

The paper is organized as follows. In Section 2 we take the standard neoclassical growth model and undertake comparative static analysis regarding the effect of technological growth on hours worked. In Section 3 we present empirical evidence regarding the positive long-run link between technological growth and hours worked. In Section 4 we analyse whether the empirical findings can be reconciled with the mechanism of the model. Finally, Section 5 provides concluding remarks.

\section{A NeOclassical Growth Model}

We analyse the effect of productivity growth on steady-state hours using a standard neoclassical growth model with exogenous labour-augmenting technological progress and optimal saving-investment decisions by households. We use the model's implications to structure our empirical analysis further below. In the model, both technology and household preferences satisfy the restrictions imposed by balanced growth facts (King et al. 1988). That is, the model has (i) a production function with constant returns to scale and labour-augmenting technological progress, and (ii) preferences that display a constant elasticity of intertemporal substitution in consumption and where the marginal rate of substitution between consumption and hours is homogeneous of degree 1 in consumption. This means that in the long run, a doubling of the level of productivity leads to a doubling of the wage rate and consumption, while leaving hours constant, as the substitution and income effects on labour supply cancel out. This level effect of productivity is distinct from the growth effect of productivity considered in the present paper. Our comparative static analysis is basically a comparison of two balanced growth paths-one associated with low productivity growth and the other associated with high productivity growth-in terms of the implied steady-state hours.

Technology and household preferences are modelled in a way similar to that in the related literature on labour supply (e.g. Prescott 2004; Ohanian et al. 2008). There is a representative household whose period utility depends on consumption $C_{t}$ and hours worked $N_{t}$ :

$$
U\left(C_{t}, N_{t}\right)=\log C_{t}+\psi \log \left(1-N_{t}\right)
$$


where $\psi>0$. The household maximizes $E_{t} \sum_{i=0}^{\infty} \beta^{i} U\left(C_{t+i}, N_{t+i}\right)$, where $\beta$ is the subjective discount factor, subject to a Cobb-Douglas production function ${ }^{2}$ in labour and capital $K_{t}$ given by

$$
Y_{t}=F\left(K_{t}, A_{t} N_{t}\right)=K_{t}^{\alpha}\left(A_{t} N_{t}\right)^{1-\alpha}
$$

(where $0<\alpha<1$, and $A_{t}$ represents exogenous labour-augmenting technology), a capital accumulation equation

$$
K_{t+1}=(1-\delta) K_{t}+I_{t}
$$

(where $I_{t}$ is investment, and $\delta$ is the depreciation rate of capital), and a resource constraint

$$
C_{t}+I_{t}=Y_{t}
$$

The first-order condition for the optimal choice of capital $K_{t+1}$ is

$$
\beta\left[\alpha \frac{Y_{t+1}}{K_{t+1}}+(1-\delta)\right]=\frac{C_{t+1}}{C_{t}} .
$$

There is a positive relationship between the output-capital ratio and consumption growth. Along the balanced growth path, the latter is pinned down by the exogenous productivity growth, so higher productivity growth leads to an increase in the outputcapital ratio.

Likewise, the first-order condition for the optimal choice of hours $N_{t}$ is

$$
\psi \frac{C_{t}}{1-N_{t}}=(1-\alpha) \frac{Y_{t}}{N_{t}}
$$

The left-hand side of equation (4) is the marginal rate of substitution ( $m r s$ ) between consumption and hours, while the right-hand side is the marginal product of labour $(m p n)$. An increase in consumption (given output) or a decline in output (given consumption) makes an additional unit of leisure more valuable than the marginal use of time in productive activities, thus calling for a drop in hours to maintain efficiency.

\section{Steady-state growth and comparative statics}

Using the capital accumulation equation (1) to substitute for $I_{t}$ in the resource constraint (2), dividing through by $K_{t}$ and imposing balanced growth $Y_{t} / K_{t}=y, C_{t} / K_{t}=c$ and $N_{t}=N$, we get

$$
c=y-\left[\Gamma_{k}-(1-\delta)\right]
$$

where $\Gamma_{k} \equiv K_{t+1} / K_{t}$. Given the output-capital ratio $y$, faster accumulation of capital reduces the steady-state consumption-capital ratio $c$. 
Similarly, the steady state of the optimal choice of capital (3) is given by

$$
\beta[\alpha y+(1-\delta)]=\Gamma_{c},
$$

where $\Gamma_{c} \equiv C_{t+1} / C_{t}$, and along a balanced growth path, $\Gamma_{c}=\Gamma_{k}=\Gamma$. Faster consumption growth $\Gamma_{c}$ implies a faster rate of decline in the marginal utility of consumption, which, by the optimality condition, necessitates a higher marginal product of capital, which is proportional to the output-capital ratio $y$.

Finally, the steady state of the optimal choice of hours (4) is given by

$$
N=\frac{1-\alpha}{1-\alpha+\psi c / y}
$$

Since from equation (6) $y=y(\Gamma)$ and from equation (5) $c=c(y(\Gamma), \Gamma)$, equation (7) can be solved for $N$ as a function of $\Gamma$ :

$$
N^{*}=\frac{1-\alpha}{1-\alpha+\psi c^{*}\left(y^{*}(\Gamma), \Gamma\right) / y^{*}(\Gamma)} .
$$

Thus for steady-state hours to rise with productivity growth $\Gamma$, the steady-state consumption-output ratio must be a decreasing function in the productivity growth. Similar to Prescott (2004), the $c / y$ term captures intertemporal factors affecting labour supply, except that here the relevant factor is trend productivity growth.

To see that $\mathrm{d} N^{*} / \mathrm{d} \Gamma>0$ (i.e. equilibrium hours must be higher for higher productivity growth), first note that the solution of the steady-state system (5)-(7) is recursive. Equation (6) determines the equilibrium output-capital ratio given productivity growth. Then equation (5) determines the equilibrium consumption-capital ratio. Finally, equation (7) determines the equilibrium labour supply. Substituting equation (6) into equation (5) gives

$$
c=y-\beta \alpha y+(1-\beta)(1-\delta),
$$

which shows that the consumption-capital ratio rises less than one-for-one with the output-capital ratio. Therefore from the optimal labour supply condition (8), hours must be higher for higher productivity growth.

Figure 1 illustrates the comparative static result. The upward sloping marginal rate of substitution between consumption and hours ( $m r s$, the left-hand side of equation (7)) rotates anticlockwise (due to higher $c$ implied by higher growth) by less than the downward sloping marginal productivity of labour ( $m p n$, the right-hand side of equation (7)) shifts rightward (due to higher $y$ implied by higher growth). As a result, equilibrium hours $N$ increase with technological growth.

\section{Model variations and quantitative effects}

In order to explore more robustly the quantitative properties of the model, we employ a constant elasticity of substitution (CES) production function, 


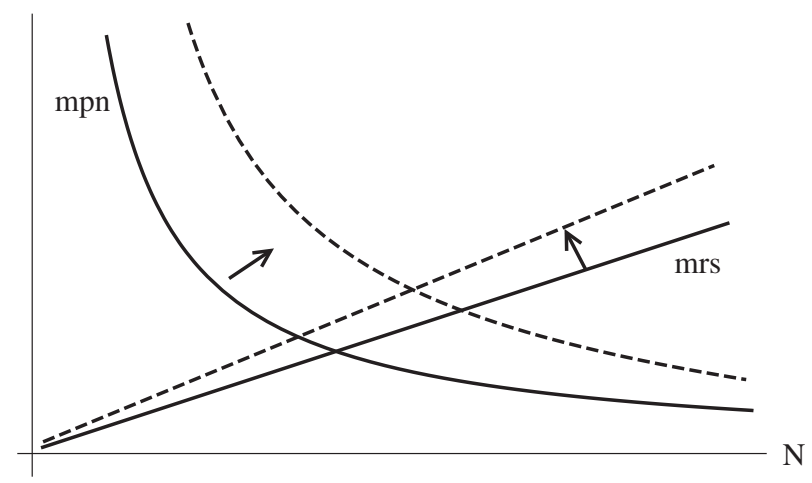

FIGURE 1. The effect of higher technological growth on steady-state hours.

$$
Y_{t}=\left[\alpha K_{t}^{\tau}+(1-\alpha)\left(A_{t} N_{t}\right)^{\tau}\right]^{1 / \tau}
$$

where $0<\alpha<1, \tau<1$, and the elasticity of substitution is given by $1 /(1-\tau)$. The CobbDouglas production function arises as a limiting case where $\tau \rightarrow 0$. The optimal steadystate capital accumulation along the balanced growth path is

$$
\Gamma=\beta\left[\alpha y^{1-\tau}+(1-\delta)\right]
$$

The larger $\tau$ (i.e. the larger the elasticity of substitution), the stronger the rise in the output-capital ratio $y$ to a given rise in productivity growth. The optimal level of steadystate hours is given by

$$
\frac{N^{1-\tau}}{1-N}=\frac{1-\alpha y^{1-\tau}}{\psi}=\frac{1-\alpha}{\psi}\left(\frac{y}{c}\right) y^{-\tau} .
$$

Compared to the Cobb-Douglas case, hours worked depend not only on the consumption-output ratio, but also on the output-capital ratio.

We solve the calibrated version of the model's steady state and consider the effect of a $1 \%$ reduction in productivity growth on steady-state hours. The scale parameter $\psi$ in the utility function is set so that the initial steady-state hours are 0.33 , which is a standard choice in the literature. As in Cooley and Prescott (1995), $\delta$ is set at 0.048 and $\alpha$ at 0.4 , while initial annual productivity growth $\Gamma$ is set at $2 \%$. As pointed out in Grossman et al. (2017), the magnitude of the elasticity of substitution is subject to debate and still controversial. Using a meta-regression analysis, Knoblach et al. (2020) report a range for the elasticity of substitution of 0.47 to 0.85 . By contrast, Karabarbounis and Neiman (2014) - who take advantage of cross-sectional variation in the relative price of investment, and focus only on long-run trends-report a value of 1.25 for the elasticity of substitution. Thus, we use three alternative values for the elasticity parameter, namely, unity (the baseline Cobb-Douglas form), 0.66 (the midpoint of the estimated range reported in Knoblach et al. (2020)), and 1.25. For these values, we find that in response 
to a $1 \%$ reduction in productivity growth, steady-state hours decline by $0.34 \%, 1.26 \%$ and $3.4 \%$, respectively.

The main results are shown using a standard closed economy growth model. In the Appendix, we present a small open economy model along the lines of Schmitt-Grohe and Uribe (2003) and Aguiar and Gopinath (2007). Unlike the closed-economy version, the open-economy model raises computational issues due to the fact that a permanent shock to domestic productivity growth implies steady-state unbalanced growth between the domestic and foreign economies. For this reason, we assume in our numerical simulations a highly persistent, but stationary process for the productivity growth shock. We find that over the longer horizon along the adjustment path, hours rise following a very persistent positive shock to domestic productivity growth (see Figure Al in the Appendix). As a very persistent rise in productivity growth implies a strong increase in future income relative to the pre-shock trend, consumption and leisure rise on impact. Along the adjustment path, consumption falls persistently relative to output (and thus hours increase persistently) as capital adjusts reflecting the productivity increase. A similar qualitative pattern is observed in Aguiar and Gopinath (2007), albeit with a less persistent growth shock (see in particular their Figure 3b).

We conclude that, overall, the basic neoclassical growth model is consistent with the joint decline in technological growth and hours observed in many countries over the postwar period. Perhaps not surprisingly, given the simplicity of the model, its precise quantitative prediction depends on the parameter configuration.

\section{THE EMPIRICAL LINK BETWEen TECHNOLOGICAL GROWTH AND HOURS}

To analyse whether the data support the model-implied positive link between technological growth and hours, we use annual data for 15 OECD countries from 1955 to 2014. Technological growth is measured by TFP growth or alternatively by labour productivity growth. TFP data are taken from the Penn World Table and are computed based on national accounts for real GDP, the capital stock (based on cumulated investment) and the labour force, together with data on capital and labour force shares (for details, see Feenstra et al. 2015). Labour productivity is measured as output per hours worked and is taken from the Total Economy Database (TED). We construct hours per working-age population in the same way as Ohanian et al. (2008) by multiplying average annual hours worked per employee with employment and dividing by the working-age population. ${ }^{3}$ Hours per employee and employment are obtained from the TED, and the working-age population from the OECD.

We extract the low-frequency components from the data series to get measures that are comparable to model-based steady-state variables. To do so, we use the HP filter and alternatively compute decade averages of the data. A similar approach is used by Bean and Pissarides (1993) to study the long-run link between technological growth and unemployment, and by Berentsen et al. (2011) to study the long-run relation between inflation and unemployment. For the HP filter, we start with a smoothing parameter of 6.25 for our annual dataset, which corresponds, according to Ravn and Uhlig (2002), to the standard smoothing parameter of 1600 for quarterly data that is often used to disentangle growth and cyclical components of macroeconomic time series. We progressively increase the smoothing parameter to 62.5 and 625 to remove more of the higher-frequency fluctuations in order to be sure that no cyclical dynamics remain. To prevent the possibility that an end-of-sample bias distorts the trend estimates, after 
filtering we cut off 8 years at the beginning and end of the sample. Hence the final sample ranges from 1963 to 2006 . This sample is also used to compute decade averages. ${ }^{4}$

\section{Trends of technological growth and hours}

The joint decline of trend technological growth and hours during the postwar period in many countries indicates a possible link between the two. Analysing this more systematically, one can show that there is indeed a strong correlation between long-run measures of technological growth and hours across countries and over time. ${ }^{5}$ It is possible, though, that these correlations are spurious and reflect the effect of unobserved variables-such as taxes-on hours and technology. The following panel analysis provides evidence to the contrary.

We use cross-country variations in the timing and size of the slowdown in technological growth to identify the effect on hours. Figure 2 shows as examples the trends of labour productivity growth and hours for six countries. France and Italy are examples of countries in which labour productivity growth falls almost monotonically over the sample. In contrast, in other countries-such as, for example, the USA and Australia-the trend of labour productivity growth shows several reversals and no clear overall trend. Labour productivity growth declines during the 1960s and 1970s. In the USA, it stabilizes from the mid-1980s to the mid-1990s, while in Australia it continues to decrease until about 1990. Afterwards, labour productivity growth increases strongly during the 1990s before decreasing again towards the end of the sample in both countries. The Netherlands and Japan are examples of intermediate cases. Overall, labour productivity growth has declined over the sample, but not continuously. In the Netherlands, the decline stops around 1980, and labour productivity shows some fluctuations, but no clear trend afterwards. In Japan, the decline in labour productivity growth is interrupted during the 1990s, during which labour productivity grew substantially.

In all countries the patterns of technological growth are at least roughly tracked by the trend of hours, though there are differences across countries. For example, in France and Japan the decline in productivity growth is accompanied by a similar decline in hours worked. In the Netherlands and Italy there is also co-movement until about the mid1990s, but afterwards the trends decouple. In the USA and Australia, hours show roughly similar trend reversals as productivity growth with an initial decline followed by a strong increase during the 1990s.

There are further differences in the patterns of trend technological growth in the other countries considered that are roughly mirrored by the trend in hours. Trend technological growth has decreased over the sample in most European countries and in Canada, with a temporary stabilization or even a slight reversal in some countries in the 1990s or around 2000. Exceptions are Finland, Sweden and the UK, which show a similar pattern with several reversals in trend labour productivity growth as in the USA and Australia.

Overall, the large differences in the patterns of technological growth between different countries and the rough co-movement with the trend of hours indicate the possibility that correlations between technological growth and hours are not spurious. Similar patterns and a similar degree of co-movement can be observed when measuring technological growth using TFP growth instead of labour productivity growth. On the other hand, the decoupling of technological growth and hours worked from time to time suggests that 

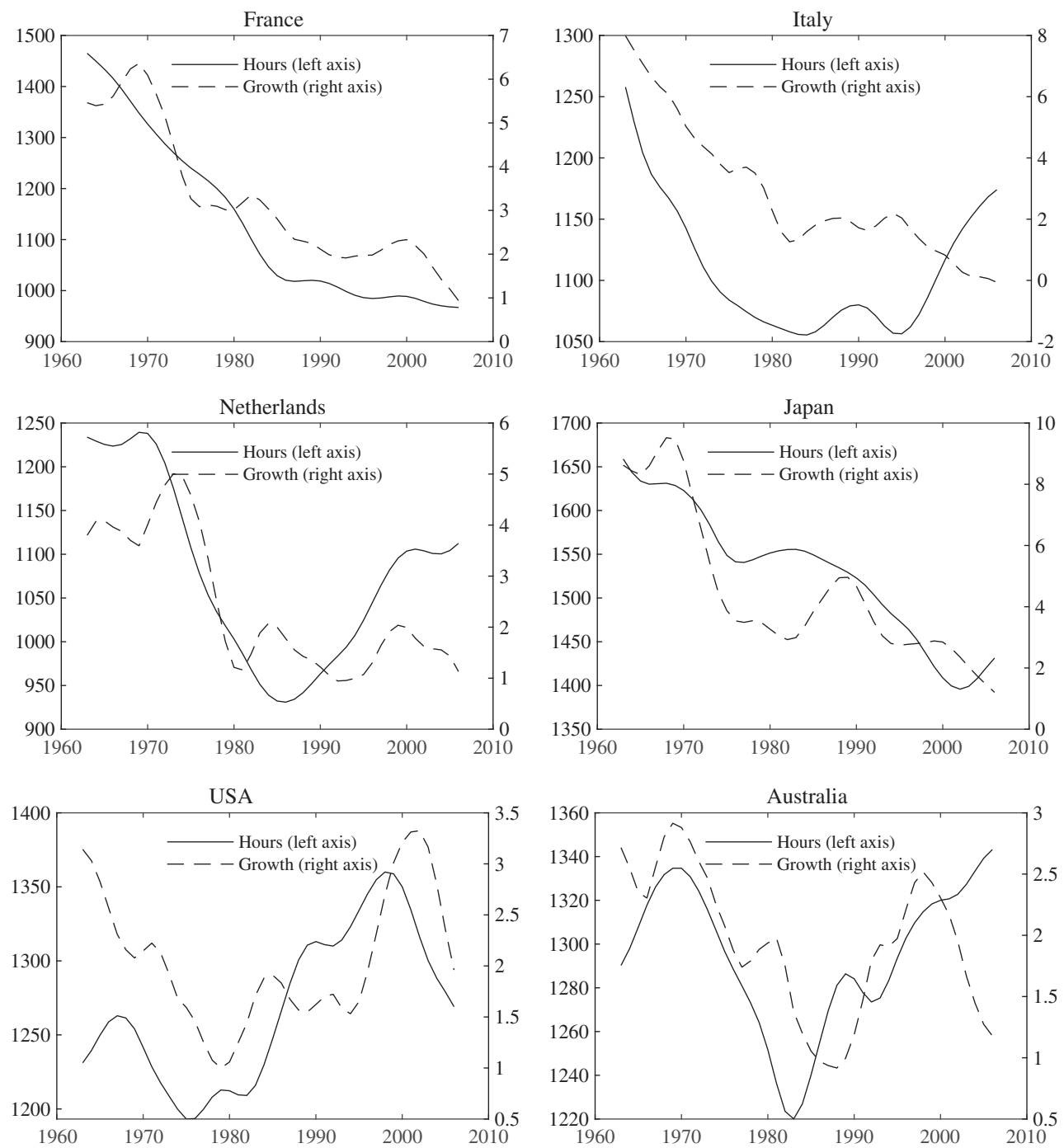

FIGURE 2. Trend hours and labour productivity growth for selected countries (HP 6.25).

other factors (e.g. taxes) are also important determinants of hours worked per workingage population.

\section{Panel estimates}

Table 1 shows panel estimates of trend hours on trend technological growth controlling for cross-country and time fixed effects. In particular, the inclusion of time fixed effects is very important as it can capture unobserved factors that led to a decline in hours in many countries. One example would be the large co-movement in taxes as documented, for example, in Ohanian et al. (2008) and McDaniel (2011) that we analyse in more detail below. The $p$-values are computed based on a circular moving block bootstrap with a 
TABLE 1

EFFECTS OF TECHNOLOGICAL GROWTH ON HOURS

\begin{tabular}{|c|c|c|c|c|c|c|c|c|}
\hline \multirow[b]{2}{*}{ Smoothing } & \multicolumn{4}{|c|}{ Labour productivity growth } & \multicolumn{4}{|c|}{ TFP growth } \\
\hline & 6.25 & 62.5 & 625 & DA & 6.25 & 62.5 & 625 & DA \\
\hline Technological growth & $\begin{array}{c}1.51 \\
(0.01)\end{array}$ & $\begin{array}{c}2.14 \\
(0.00)\end{array}$ & $\begin{array}{c}2.85 \\
(0.00)\end{array}$ & $\begin{array}{c}1.58 \\
(0.20)\end{array}$ & $\begin{array}{c}0.91 \\
(0.15)\end{array}$ & $\begin{array}{c}1.57 \\
(0.04)\end{array}$ & $\begin{array}{c}2.71 \\
(0.00)\end{array}$ & $\begin{array}{c}0.86 \\
(0.56)\end{array}$ \\
\hline$R^{2}$ & 0.83 & 0.84 & 0.87 & 0.83 & 0.82 & 0.83 & 0.87 & 0.82 \\
\hline Observations & 660 & 660 & 660 & 75 & 660 & 660 & 660 & 75 \\
\hline
\end{tabular}

Notes

The estimated coefficients refer to the effects of different measures of technological growth on hours, in \%. The row smoothing indicates the HP parameter or the usage of decade averages (DA). All results are based on panel estimates controlling for cross-sectional and time fixed effects. The $p$-values (in parentheses) are based on a circular moving block bootstrap with 100,000 draws and a block size of 4, except for the regressions based on decade averages, for which we use a block size of 2 .

block size of 4 for the regressions based on HP filtered data, and 2 for those based on decade averages with 100,000 draws.

We find a sizeable effect of technological growth on hours that is highly significant in most specifications. An increase of technological growth by 1 percentage point leads to an increase in hours between $0.9 \%$ and $2.9 \%$. The effect of technological growth on hours increases with the degree of smoothing and is larger if labour productivity rather than TFP is used to measure technological growth.

\section{The effect of taxes}

We check the robustness of our results when controlling for the effect of taxes on hours. Taxes have been found in previous studies to be a major determinant of the changes of labour supply over time (e.g. Prescott 2004; Ohanian et al. 2008; McDaniel 2011). Taxes might also have a direct effect on technological growth. For example, higher taxes reduce technological growth via factor price distortions (Feldstein 2006) or the effects on entrepreneurial activities (Gentry and Hubbard 2000; Cullen and Gordon 2007). Then it could be that taxes are the driving force behind the observed link between technological growth and hours, at least to some degree.

We construct three effective tax rates as in McDaniel (2011), which uses a neoclassical growth model to derive these measures. The first is the effective labour income tax that distorts the representative household's intratemporal optimality condition:

$$
\tau_{t}^{h}=\frac{\tau_{t}^{\mathrm{Ss}}+\phi \tau_{t}^{\mathrm{inc}}+\tilde{\tau}_{t}^{\mathrm{c}}}{1+\tilde{\tau}_{t}^{\mathrm{c}}},
$$

where $\tau^{\text {inc }}$ denotes the average labour income tax rate, $\tau^{\text {ss }}$ denotes the average payroll tax rate, and $\tilde{\tau}^{\mathrm{c}}$ denotes the average tax on consumption expenditure. The parameter $\varphi$ scales the average income tax rate to create a marginal income tax rate and is calibrated to 1.6 as in McDaniel (2011), which uses the same data. The intertemporal optimality condition is distorted by two effective tax rates. The first is the effective capital tax $\tau_{t}^{k}$. It is a function of the average tax on capital income $\tilde{\tau}_{t}^{k}$ and the average tax on investment expenditure $\tilde{\tau}_{t}^{x}$ : 


$$
\tau_{t}^{k}=\frac{\tilde{\tau}_{t}^{k}+\tilde{\tau}_{t}^{x}}{1+\tilde{\tau}_{t}^{x}} .
$$

The second distortion of the intertemporal optimality condition is ${ }^{6}$

$$
\tau_{t}^{c x}=\frac{\left(1+\tilde{\tau}_{t}^{\mathrm{c}}\right)\left(1+\tilde{\tau}_{t+1}^{x}\right)}{\left(1+\tilde{\tau}_{t+1}^{\mathrm{c}}\right)\left(1+\tilde{\tau}_{t}^{x}\right)}-1 .
$$

It differs from zero only if the taxes on consumption and investment grow at different rates.

Data on average tax rates are taken from McDaniel (2006) and are available for all 15 OECD countries studied above. We construct effective tax rates and estimate their trends in the same way as for hours and technological growth. Plots of the three tax wedges for all 15 countries are shown in the Appendix. The effective labour tax rate has increased in most countries over the sample. Increases in the USA and in Australia are modest, while the increase in most European countries is large. An exception is the Netherlands, where the effective labour tax rate has declined from 1980 to about 1995. The trend of the effective capital tax rate differs across countries. Most European countries show an increase over time-interrupted by a temporary decrease in some cases. An exception is Germany, where the effective capital tax rate has declined since 1980. In Japan, the effective capital tax rate increases in the first half of the sample and declines afterwards, while it declines in the USA until 1980 and stabilizes thereafter. In Australia, an overall increase can be observed, while in Canada there are several trend reversals. Overall, the dispersion across countries is small for the effective capital tax rate compared to the effective labour tax. Finally, $\tau^{c x}$ is basically zero for all countries throughout the whole sample.

The effective labour and capital tax rates enter the regression in logs, while the third effective tax rate enters in levels as it takes positive as well as negative values. The regression includes, as before, cross-country and time fixed effects. Table 2 shows the estimates. We find that the effective labour tax has a highly significant effect on hours worked in the specifications where HP parameters 6.25 or 62.5 are used to extract the trends in the data. This confirms earlier findings in the literature that, in particular, changes in the labour tax rates are crucial for explaining changes in hours. An increase in the effective labour tax rate by $1 \%$ decreases hours by up to $0.17 \%$. Importantly, even when controlling for taxes, we still find a highly significant link between technological growth and hours worked roughly in the same range as in Table 1. Only when using decade averages to extract trends is the effect insignificant. The effect is again higher when measuring technological growth based on labour productivity rather than on TFP growth, and increases with the degree of smoothing.

\section{Are the results robust?}

The decline in hours is particular large in France and Germany, so these outliers could potentially have a large impact on the panel estimates. Therefore we repeat the panel estimates and exclude France and Germany from the sample (see Table 3). The effect declines somewhat compared to the baseline estimates in Table 1, but is still sizeable and significant except when using decade averages to measure long-run trends. 
TABLE 2

CONTROLLING FOR TAXES

\begin{tabular}{|c|c|c|c|c|c|c|c|c|}
\hline \multirow[b]{2}{*}{ Smoothing } & \multicolumn{4}{|c|}{ Labour productivity growth } & \multicolumn{4}{|c|}{ TFP growth } \\
\hline & 6.25 & 62.5 & 625 & DA & 6.25 & 62.5 & 625 & DA \\
\hline \multirow[t]{2}{*}{ Technological growth } & 1.47 & 2.30 & 3.71 & 2.25 & 0.86 & 1.81 & 3.59 & 1.29 \\
\hline & $(0.01)$ & $(0.00)$ & $(0.00)$ & $(0.11)$ & $(0.19)$ & $(0.02)$ & $(0.00)$ & $(0.37)$ \\
\hline \multirow[t]{2}{*}{$\tau^{h}$} & -0.14 & -0.10 & -0.01 & -0.11 & -0.17 & -0.14 & -0.07 & -0.15 \\
\hline & $(0.04)$ & $(0.16)$ & $(0.90)$ & $(0.60)$ & $(0.01)$ & $(0.03)$ & $(0.29)$ & $(0.41)$ \\
\hline \multirow[t]{2}{*}{$\tau^{k}$} & 0.09 & 0.09 & 0.11 & 0.14 & 0.08 & 0.08 & 0.10 & 0.12 \\
\hline & $(0.14)$ & $(0.13)$ & $(0.12)$ & $(0.37)$ & $(0.22)$ & $(0.19)$ & $(0.15)$ & $(0.41)$ \\
\hline \multirow[t]{2}{*}{$\tau^{c x}$} & -3.37 & -5.90 & -5.87 & 9.17 & -3.43 & -7.25 & -12.00 & 7.57 \\
\hline & $(0.18)$ & $(0.16)$ & $(0.34)$ & $(0.16)$ & $(0.17)$ & $(0.08)$ & $(0.05)$ & $(0.20)$ \\
\hline$R^{2}$ & 0.84 & 0.85 & 0.88 & 0.85 & 0.83 & 0.84 & 0.87 & 0.83 \\
\hline Observations & 660 & 660 & 660 & 75 & 660 & 660 & 660 & 75 \\
\hline
\end{tabular}

Notes

See Table 1.

TABLE 3

EXCLUDING FRANCE AND GERMANY

\begin{tabular}{|c|c|c|c|c|c|c|c|c|}
\hline \multirow[b]{2}{*}{ Smoothing } & \multicolumn{4}{|c|}{ Labour productivity growth } & \multicolumn{4}{|c|}{ TFP growth } \\
\hline & 6.25 & 62.5 & 625 & DA & 6.25 & 62.5 & 625 & DA \\
\hline Technological growth & $\begin{array}{c}1.28 \\
(0.02)\end{array}$ & $\begin{array}{c}1.81 \\
(0.00)\end{array}$ & $\begin{array}{c}2.36 \\
(0.00)\end{array}$ & $\begin{array}{c}1.28 \\
(0.25)\end{array}$ & $\begin{array}{c}0.74 \\
(0.21)\end{array}$ & $\begin{array}{c}1.29 \\
(0.05)\end{array}$ & $\begin{array}{c}2.22 \\
(0.00)\end{array}$ & $\begin{array}{c}0.65 \\
(0.61)\end{array}$ \\
\hline$R^{2}$ & 0.86 & 0.87 & 0.91 & 0.87 & 0.85 & 0.87 & 0.90 & 0.86 \\
\hline Observations & 572 & 572 & 572 & 65 & 572 & 572 & 572 & 65 \\
\hline
\end{tabular}

Notes

See Table 1.

The results could also be influenced by the rebuilding of Europe in the aftermath of the Second World War. Hence we repeat the estimates, but exclude data prior to 1970 . Table 4 shows that the effects are slightly larger for small smoothing parameters and slightly smaller for large smoothing parameters, compared to the baseline results. However, the overall pattern is virtually unchanged, providing evidence that the results are not driven by catch-up effects after the Second World War.

Another factor influencing our results might come from the rise of female labour supply during the sample period. Unfortunately, data constraints prevent us from running the same exercise as before using gender-specific data. If that were possible, then we could focus on the effect of technological growth on hours worked by men where there is no such large trend change as for females, though the rise in the female labour participation rate might have also affected hours worked by men. In particular, genderspecific international long time series on hours worked are not available, which is why the literature focuses on explaining changes in the female labour force participation rate (see, for example, Fernández et al. 2004; Attanasio et al. 2008; Jones et al. 2015). Thus we control for the female labour force participation rate (LFPR) in a smaller sample to 
TABLE 4

RESUlTS USING DATA From 1970 ONWARDS

\begin{tabular}{lcccccccc}
\hline & \multicolumn{6}{l}{ Labour productivity growth } & & \multicolumn{1}{l}{ TFP growth } \\
\cline { 2 - 4 } Smoothing & 6.25 & 62.5 & 625 & & 6.25 & 62.5 & 625 \\
\hline Technological growth & 1.73 & 2.23 & 2.74 & & 1.10 & 1.64 & 2.42 \\
& $(0.01)$ & $(0.00)$ & $(0.00)$ & & $(0.15)$ & $(0.09)$ & $(0.02)$ \\
$R^{2}$ & 0.84 & 0.86 & 0.90 & & 0.84 & 0.85 & 0.89 \\
Observations & 555 & 555 & 555 & & 555 & 555 & 555 \\
\hline
\end{tabular}

Notes

See Table 1.

control at least to some extent for the rise in female labour supply. We stress, however, that this analysis is only tentative since it considers only the extensive margin of female labour supply, while it leaves changes along the intensive margin aside. Data for the female LFPR are available from the OECD Labour Force Statistics for the period 19752014, and the country coverage excludes Austria, Belgium, Canada, Switzerland and the UK compared to our original sample. Table 5 presents the the panel estimates for this sample. For each smoothing parameter, the respective first column depicts the results without controlling for LFPR, and the second column depicts the results controlling for LFPR. We obtain a highly significant link between hours and technological growth even when we control for LFPR. Results are very similar with and without controlling for LFPR. Compared to our baseline results, the magnitude of the effect of technological progress on hours is considerably smaller, but this is driven by the change in the sample compared to our baseline estimates rather than by controlling for LFPR. Finally, the increase in female labour supply could lead to an increase in hours in the R\&D sector that increases technological growth. Such reverse causality is unlikely to affect our regression results, as such an effect of hours on technological growth would most likely occur with a time lag.

Overall, the highly significant positive link between technological growth and hours is very robust, though its size varies depending on the specific sample and countries considered. It is unlikely that the results are spurious as the pace of the slowdown in technological growth differs across countries, and the effect on hours remains even when controlling for time fixed effects and taxes. Further, it is unlikely that there is reverse causality. While hours might have an effect, in particular, on labour productivity over the business cycle_for example, via labour hoarding — we study long-run trends where such effects should be filtered out.

\section{Are the effects economically significant?}

The various estimates show that the effect of technological growth on hours is statistically significant. Is it also economically important? Labour productivity growth decreases over the sample on average by 3.3 percentage points across the 15 countries, and TFP growth decreases by 1.8 percentage points. The effect on hours can be computed by multiplying these change with the regression coefficients from Table 1. Accordingly, the decline in labour productivity growth leads to a decline in hours in the range $5-9 \%$, while the effect based on TFP growth is smaller, in the range $1.5-5 \%$. Hours 


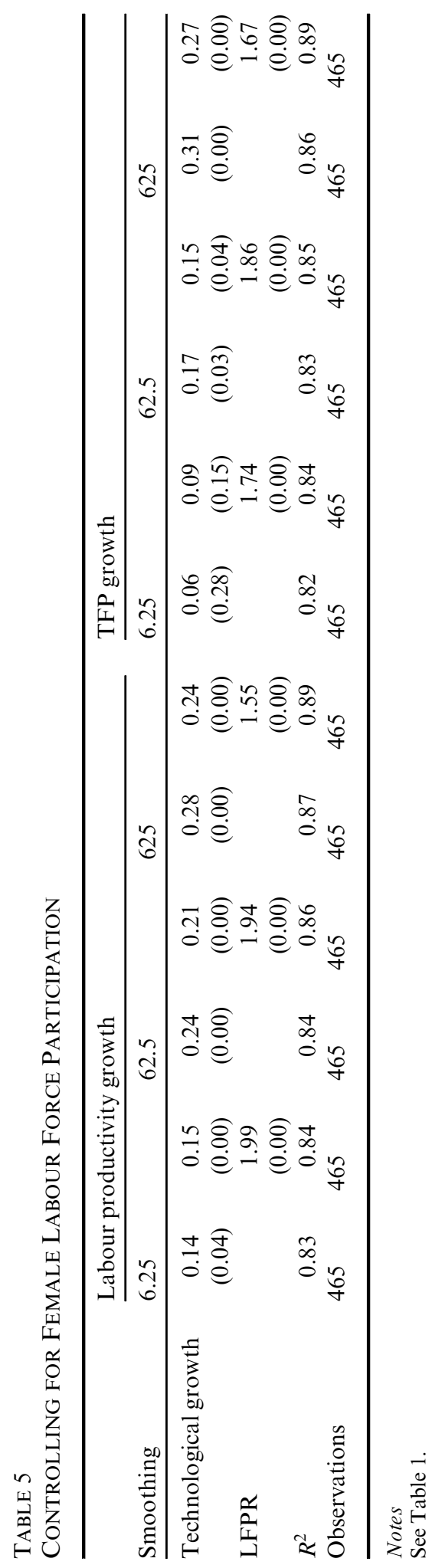


fell on average by $14.4 \%$ over the sample across the 15 countries. Hence the decline in technological growth can explain between $10 \%$ and $65 \%$ of this decline. Even the lower bound of this range would be a sizeable effect that should not be ignored. For comparison, the effective labour tax rate increases on average across the 15 countries by $60.8 \%$ (we look here at $\%$, not percentage points, as the labour tax enters the regression in logs) over the sample, leading to a decline in hours of between $0.6 \%$ and $10 \%$ (based on the coefficients of $\tau^{h}$ in Table 2). Hence the effects of technological growth and the effective labour tax rate on hours are in a similar range.

\section{THE Role OF THE CONSUMPTION-OUTPUT RATIO}

In this section, we investigate whether the positive link between technological progress and hours can be reconciled with the theoretical mechanism of the standard neoclassical growth model. As highlighted in Section 2, in the model trend technological growth has a negative effect on the trend consumption-output ratio $(\mathrm{C} / \mathrm{Y})$, which in turn affects trend hours negatively. Empirically, these two correlations are indeed negative when considering all 15 countries in the sample. The correlation is -0.12 for technological growth based on labour productivity and $\mathrm{C} / \mathrm{Y}$, and it is -0.32 for $\mathrm{C} / \mathrm{Y}$ and hours.

There is considerable cross-country heterogeneity, though. For 11 out of 15 countries, both correlations are negative, but even among those 11 countries there is substantial heterogeneity. Negative correlations between technological growth and $\mathrm{C} / \mathrm{Y}$ range from -0.93 (France) to -0.12 (Belgium), and the range is even larger for $\mathrm{C} / \mathrm{Y}$ and hours, ranging from -0.91 (France) to -0.02 (USA). To illustrate the cross-country differences, Figure 3 shows the trends of technological growth and $\mathrm{C} / \mathrm{Y}$, and Figure 4 illustrates the trends of $\mathrm{C} / \mathrm{Y}$ and hours for the same six countries, for which we showed the link between technological growth (labour productivity growth) and hours in Figure 2. The correlation coefficients are included in each graph.

Having looked rather qualitatively via the signs of correlations for evidence regarding the model mechanism, we can also examine whether the model predictions hold quantitatively. We restrict the analysis to the subset of 11 countries for which both correlations are negative, so that the necessary condition for the model mechanism is fulfilled. ${ }^{7}$ To this end, we conduct an exercise along the lines of Prescott (2004) and Ohanian et al. (2008). The starting point is the first-order condition for the optimal choice of hours given by equation (4). To be comparable with previous studies and to take into account our findings from the previous section regarding the importance of taxes, we augment the model by including taxes on labour income and consumption expenditures, and we focus on the Cobb-Douglas case rather than other parametrizations of a CES production function discussed above. In the case of the Cobb-Douglas specification, the modified first-order condition solved for hours is given by

$$
N_{t}=\frac{1-\alpha}{1-\alpha+\psi C_{t} /\left[\left(1-\tau_{t}\right) Y_{t}\right]},
$$

where $\tau_{t}$ is the tax wedge. We use equation (9) to generate values for hours given data for the consumption-output ratio and the tax wedge. ${ }^{8}$ As for the empirical exercise, we use HP filtered data to focus on long-run relations, and we cut off the initial and final 8 years of the filtered sample to avoid an end-of-sample bias that might distorts the trend 

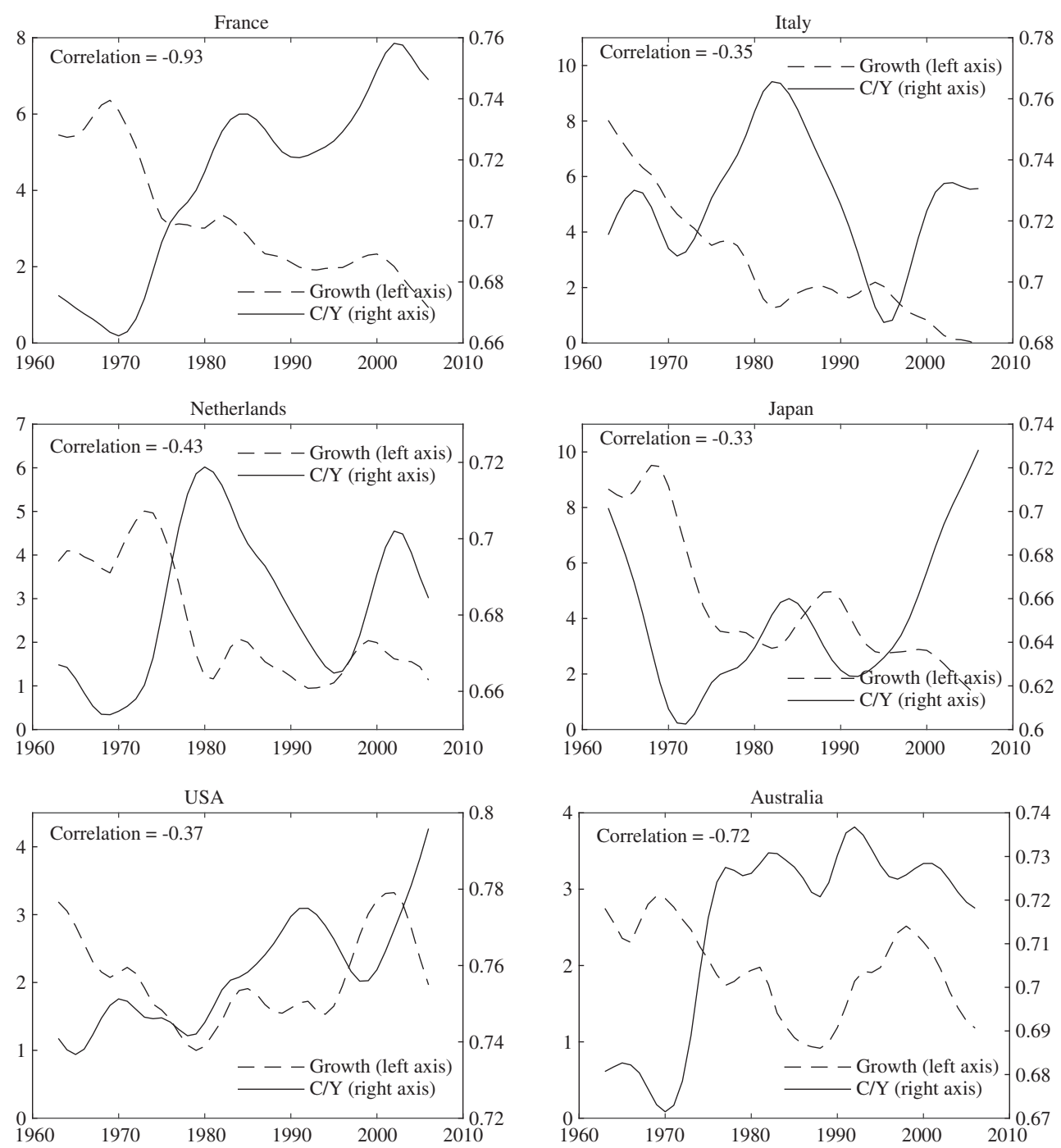

FIGURE 3. Trend labour productivity growth and trend consumption-output ratio (HP 6.25).

estimates. The tax wedge is taken from McDaniel (2006). Data on output and consumption are taken from the Penn World Tables. As in Ohanian et al. (2008), we calibrate $\alpha$ and $\psi$ such that for each country, hours predicted by the model equal actual hours in the base year 1956. ${ }^{9}$

Figure 5 shows the time path of average trend hours for the 11 countries (solid line) along with hours generated by the model when including tax wedge data only (dashed line) and when including tax wedge and $\mathrm{C} / \mathrm{Y}$ data (dashed-dotted line). Evidently, including only taxes provides reasonable predictions for the evolution of trend hours. The model correctly predicts the long-run decline in hours and the stabilization in the post-2000 period. This result is in line with previous studies that highlight the importance of taxes for explaining fluctuations in hours (see, for instance, Prescott 2004; Ohanian et al. 2008). However, the figure also shows that including $\mathrm{C} / \mathrm{Y}$ further improves the model's predictions. Including $\mathrm{C} / \mathrm{Y}$, the model captures the size of the decline of hours 

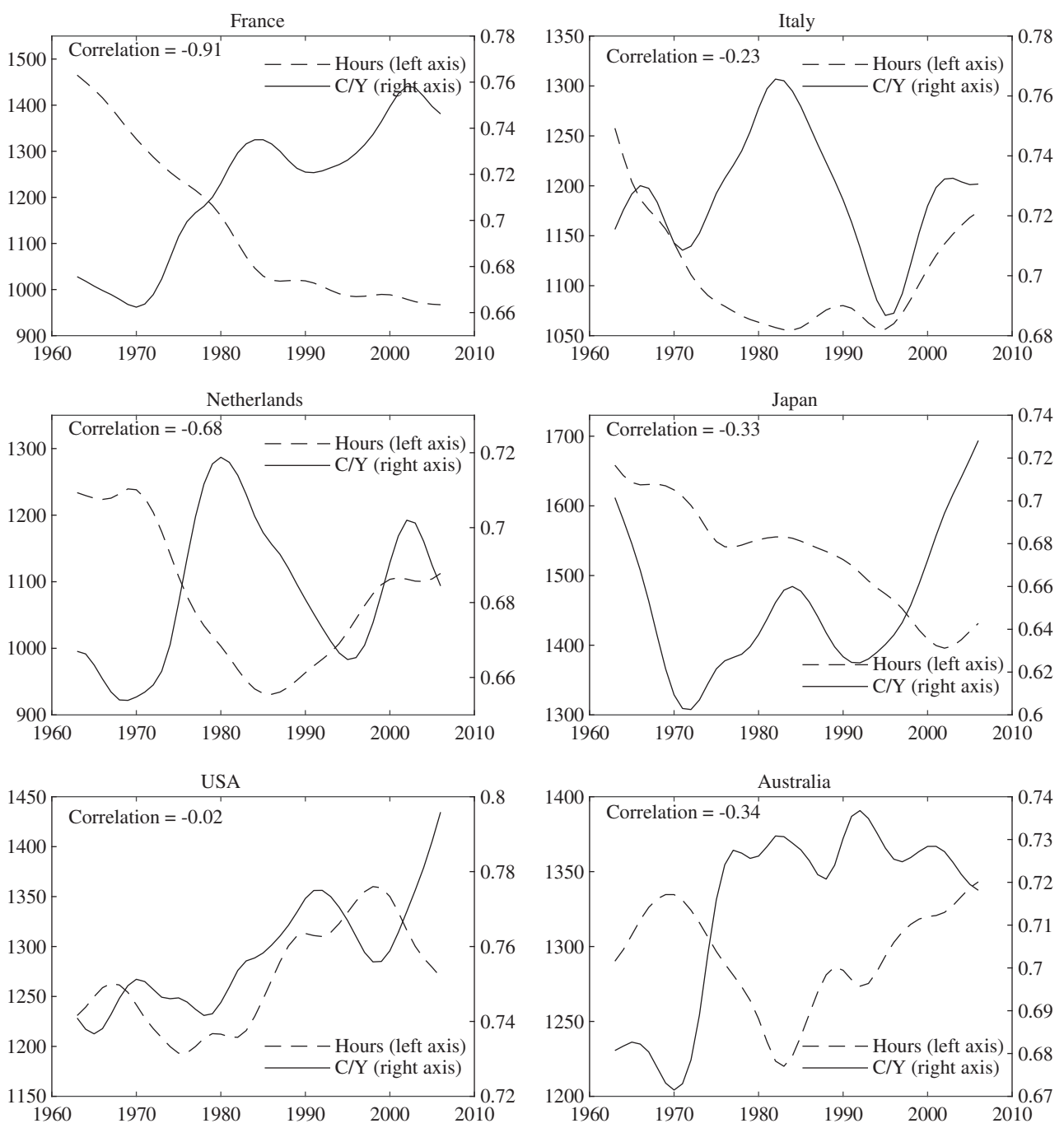

FIGURE 4. Trend hours and trend consumption-output ratio (HP 6.25).

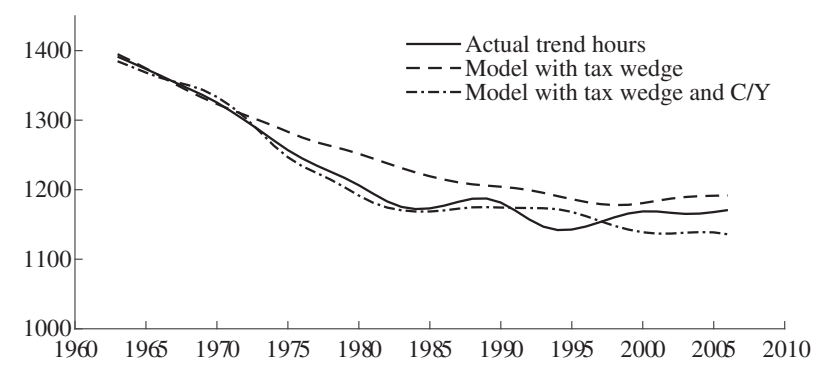

FIGURE 5. Actual hours vs. model hours. 
very precisely, while when using tax wedge data only, a gap remains in particular during the 1970 s and 1980 s.

Overall, we conclude that evidence for the mechanism of the standard neoclassical growth model is mixed. For 11 out of 15 countries, correlations in the data are in line with the model predictions, and for these countries the inclusion of $\mathrm{C} / \mathrm{Y}$ also qualitatively improves the model's explanatory power regarding long-run trends in hours. On the other hand, for 4 out of 15 countries, the correlations have the wrong sign. Further, our analysis shows that the trend in $\mathrm{C} / \mathrm{Y}$ plays only a secondary role in explaining trend hours after taxes, because variations in the consumption-output ratio are empirically rather small. While this result is in line with the model-based literature (see, for instance, Ohanian et al. 2008; McDaniel 2011), our panel estimates indicate that empirically both taxes and growth are important determinants for fluctuations in trend hours. This indicates that there might be other channels through which technological growth affects hours in the long run, on top of the effect of technological-growth-induced changes in $\mathrm{C} /$ Y. An alternative explanation might be that there are factors not included in the model affecting $\mathrm{C} / \mathrm{Y}$ that counteract the effect of technological growth, so that the overall variations in $\mathrm{C} / \mathrm{Y}$ are rather small.

\section{CONCLUDING REMARKS}

We analyse the long-run effect of permanent changes in technological growth on hours. We first show that the standard neoclassical growth model with exogenous technology implies a positive link between technological growth and steady-state hours. We then show empirically that there is indeed a significant positive long-run effect of technological growth on hours worked per capita in 15 OECD countries. These results suggest that technological growth is an important factor in explaining trends in hours worked. While the role of other factors-such as taxes, labour market institutions, and social security systems-has been analysed in the context of cross-country differences, our empirical results suggest that in particular for trends of hours per capita over time within a country, the long-run level of technological growth is also very important.

\section{ACKNOWLEDGMENTS}

The views expressed in this paper are those of the authors and do not necessarily coincide with the views of the Deutsche Bundesbank or the Eurosystem.

Funding Statement: Open Access funding enabled and organized by Projekt DEAL.

WOA Institution: UNIVERSITAET MANNHEIMBlended DEAL: Projekt DEAL

\section{NOTES}

1. Bick et al. (2017) analyse differences in hours worked across a sample of 81 countries, including all income levels, and find even larger differences. However, our focus here is on the steady-state link between technological growth and hours, so that we focus on OECD countries and exclude low-income economies that might have not yet reached a long-run steady state.

2. In the second subsection of Section 1 we show that the qualitative properties of the model also hold in the case of a CES production function.

3. Due to data revisions in hours, the final time series show some differences from those used by Ohanian et al. (2008) (see Bicket al. (2019) for an analysis of these data revisions).

4. Hamilton (2018) criticizes the usage of the HP filter and proposes an alternative regression-based filter. Using the Hamilton filter is, however, problematic in our context. The extracted trend is not smooth (Quast and Wolters 2020), and extracting cycles of different frequencies is not straightforward. Therefore we use the HP 
filter, but deal with its end-of-sample bias by cutting off observations at the beginning and end of the sample. Further, to check robustness, we also compute decade averages of the data.

5. Scatterplots and simple regressions are provided in the Appendix.

6. See equations (5)-(7) in McDaniel (2011).

7. The sample consists of Australia, Belgium, Finland, France, Germany, Italy, the Netherlands, Sweden, Spain, the UK and the USA.

8. For this analysis, we include government consumption and, as in Ohanian et al. (2008), treat it as a perfect substitute for private consumption.

9. $\alpha$ and $\psi$ enter equation (9) as constants of proportionality and thus are irrelevant for explaining fluctuations in hours relative to a base year. Given this calibration, we predict hours for the period 1957-2006 for each country.

\section{REFERENCES}

Aghion, P. and Howitt, P. (1994). Growth and unemployment. Review of Economic Studies, 61(3), 477-94.

Aguiar, M. and Gopinath, G. (2007). Emerging market business cycles: the cycle is the trend. Journal of Political Economy, 115(1), 69-102.

Alesina, A., Glaeser, E. and Sacerdote, B. (2005). Work and leisure in the United States and Europe: why so different? NBER Macroeconomics Annual, 20, 1-64.

Alonso-Ortiz, J. (2014). Social security and retirement across the OECD. Journal of Economic Dynamics and Control, 47, 300-16.

Attanasio, O., Low, H. and Sanchez-Marcos, V. (2008). Explaining changes in female labor supply in a lifecycle model. American Economic Review, 98(4), 1517-22.

BEAN, C. and Pissarides, C. (1993). Unemployment, consumption and growth. European Economic Review, 37 (4), 837-59.

Berentsen, A., Menzio, G. and Wright, R. (2011). Inflation and unemployment in the long run. American Economic Review, 101(1), 371-98.

Bick, A., Brüggemann, B. and Fuchs-Schündeln, N. (2019). Data revisions of aggregate hours worked series: implications for the Europe-US hours gap. Federal Reserve Bank of St Louis Review, 101(1), 45-56.

BICK, A. and FuCHS-SCHüNDELN, N. (2018). Taxation and labor supply of married couples across countries: a macroeconomic analysis. Review of Economic Studies, 85(3), 1543-76.

Bick, A., Fuchs-Schündeln, N. and Lagakos, D. (2017). How do average hours worked vary with development? Cross-country evidence and implications. American Economic Review, 108(1), 170-99.

Boppart, T. and Krusell, P. (2020). Labor supply in the past, present, and future: a balanced-growth perspective. Journal of Political Economy, 128(1), 118-57.

Cooley, T. F. and Prescott, E. C. (1995). Economic growth and business cycles. In T. F. Cooley (ed.), Frontiers of Business Cycle Research, 2nd edn. Princeton, NJ: Princeton University Press.

Cullen, J. B. and Gordon, R. H. (2007). Taxes and entrepreneurial risk-taking: theory and evidence for the US. Journal of Public Economics, 91(7-8), 1479-505.

ERIKSSON, C. (1997). Is there a trade-off between employment and growth? Oxford Economic Papers, 49(1), 7788.

Erosa, A., Fuster, L. and Kambourov, G. (2012). Labor supply and government programs: a cross-country analysis. Journal of Monetary Economics, 59(1), 84-107.

Feenstra, R. C., InklaAr, R. and Timmer, M. C. (2015). The next generation of the Penn World Table. American Economic Review, 105(10), 3150-82.

FeldStein, M. (2006). The effect of taxes on efficiency and growth. NBER Working Paper no. 12201.

FERnández, R., Fogli, A. and Olivetti, C. (2004). Mothers and sons: preference formation and female labor force dynamics. Quarterly Journal of Economics, 119(4), 1249-99.

Gale, W. G. and SAmwick, A. A. (2017). Effects of income tax changes on economic growth. In A. J. Auerbach and K. Smetters (eds), The Economics of Tax Policy. Oxford: Oxford University Press, pp. 13-39.

Gali, J. (1999). Technology, employment, and the business cycle: do technology shocks explain aggregate fluctuations? American Economic Review, 89(1), 249-71.

Gentry, W. M. and Hubbard, R. G. (2000). Tax policy and entrepreneurial entry. American Economic Review, 90(2), 283-7.

Gordon, R. (2016). The Rise and Fall of American Growth: The U.S. Standard of Living Since the Civil War, 2nd edn. Princeton, NJ: Princeton University Press.

Grossman, G. M., Helpman, E., Oberfield, E. and Sampson, T. (2017). Balanced growth despite Uzawa. American Economic Review, 107(4), 1293-312. 
Hamilton, J. D. (2018). Why you should never use the Hodrick-Prescott filter. Review of Economics and Statistics, 100(5), 831-43.

Jones, L. E., Manuelli, R. E. and McGrattan, E. R. (2015). Why are married women working so much? Journal of Demographic Economics, 81(1), 75-114.

Karabarbounis, L. and NeIMAN, B. (2014). The global decline of the labor share. Quarterly Journal of Economics, 129(1), 61-103.

King, R., Plosser, C. and Rebelo, S. (1988). Production growth and business cycles: I. The basic neoclassical model. Journal of Monetary Economics, 21(2-3), 195-232.

Knoblach, M., Roessler, M. and Zwerschke, P. (2020). The elasticity of substitution between capital and labour in the US economy: a meta-regression analysis. Oxford Bulletin of Economics and Statistics, 82(1), $62-82$.

MCDANIEL, C. (2006). Effective tax rates for 15 OECD countries: 1950-2003. Mimeo, Arizona State University.

MCDANIEL, C. (2011). Forces shaping hours worked in the OECD, 1960-2004. American Economic Journal: Macroeconomics, 3(4), 27-52.

NGAI, L. R. and Pissarides, C. (2008). Trends in hours and economic growth. Review of Economic Dynamics, 11(2), 239-56.

OECD (1998). Working time trends. In OECD Employment Outlook 1998. Paris: OECD Publishing.

OHAniAn, L. E., RAFFo, A. R. and Rogerson, R. (2008). Long-term changes in labor supply taxes: evidence from OECD countries, 1956-2004. Journal of Monetary Economics, 55(8), 1353-62.

PISSARIDES, C. (2000). Equilibrium Unemployment Theory, 2nd edn. Cambridge, MA: MIT Press.

Prescott, E. C. (2004). Why do Americans work so much more than Europeans? Federal Reserve Bank of Minneapolis Quarterly Review, 28, 2-13.

QuAst, J. and Wolters, M. H. (2020). Reliable real-time output gap estimates based on a modified Hamilton filter. Journal of Business \& Economic Statistics, forthcoming; available online at https://doi.org/10.1080/ 07350015.2020.1784747 (accessed 19 June 2021).

Ravn, M. O. and Uhlig, H. (2002). On adjusting the Hodrick-Prescott filter for the frequency of observations. Review of Economics and Statistics, 84(2), 371-5.

Rogerson, R. (2006). Understanding differences in hours worked. Review of Economic Dynamics, 9(3), 365-409.

Schmitt-Grohe, S. and Uribe, M. (2003). Closing small open economy models. Journal of International Economics, 61(1), 163-85.

Tesfaselassie, M. F. and Wolters, M. H. (2018). The impact of growth on unemployment in a low vs. a high inflation environment. Review of Economic Dynamics, 28, 34-50.

WALlENIUS, J. (2013). Social security and cross-country differences in hours: a general equilibrium analysis. Journal of Economic Dynamics and Control, 37(12), 2466-82.

\section{APPENDIX}

\section{A SMALL OPEN-ECONOMY MODEL}

The small open economy is modelled following Schmitt-Grohe and Uribe (2003) and Aguiar and Gopinath (2007). The model features a debt instrument $B_{t}$ and (to induce stationarity) a debtsensitive interest rate on borrowing by the domestic households:

$$
R_{t}=R^{*}+\phi\left[\exp \left(b_{t}-b\right)-1\right]
$$

where $R^{*}$ is the world interest rate and thus exogenous to the domestic economy, and $b_{t} \equiv B_{t} / A_{t-1}$ is detrended debt (as in Aguiar and Gopinath 2007). The production function is Cobb-Douglas, and the resource constraint in stationary form is

$$
\Gamma_{t} b_{t+1}=\left(R^{*}+\phi\left[\exp \left(b_{t}-b\right)-1\right]\right) b_{t}-y_{t}+c_{t}+\left[\Gamma_{t} k_{t+1}-(1-\delta) k_{t}\right],
$$

where for any variable $X_{t}$, we define $x_{t} \equiv X_{t} / A_{t-1}$. The representative domestic household chooses sequences of consumption, hours, physical capital and debt so as to maximize intertemporal utility given in the main text. 
Combining the first-order conditions with respect to consumption and debt yields

$$
1=\beta\left(R^{*}+\phi\left[\exp \left(b_{t}-b\right)-1\right]\right) \frac{c_{t}}{\Gamma_{t} c_{t+1}} .
$$

Combining the first-order conditions with respect to consumption and capital gives

$$
1=\beta\left(\alpha \frac{y_{t+1}}{k_{t+1}}+1-\delta\right) \frac{c_{t}}{\Gamma_{t} c_{t+1}} .
$$

The optimal level of hours worked in stationary form is

$$
N_{t}=\frac{1-\alpha}{1-\alpha+\psi c_{t} / y_{t}}
$$

The production function in stationary form is

$$
y_{t}=k_{t}^{\alpha}\left(\Gamma_{t} N_{t}\right)^{1-\alpha} .
$$

Finally, we specify an AR process for $\log \Gamma_{t}$ :

$$
\log \Gamma_{t}=(1-\rho) \log \Gamma+\rho \log \Gamma_{t-1}+e_{t}
$$

The model is calibrated at an annual frequency, as in Schmitt-Grohe and Uribe (2003): $\beta=0.96$, $b=0.7442, \varphi=0.000742, \delta=0.1, R^{*}=\Gamma / \beta$, where steady-state annual productivity growth $\Gamma$ is set at $2 \%$. As in the main text, $\alpha=0.32$ and the scale parameter $\psi$ in the utility function is set so that steady state hours are 0.33 .

Due to computational issues arising from unbalanced growth associated with a permanent shock to domestic productivity growth, we assume in our simulations a highly persistent but stationary process for the productivity growth shock. To be specific, we set $\rho$ equal to 0.999 and focus on the longer-term dynamics of the economy. Figure A1 shows the impulse response functions (expressed as absolute deviation from steady state) of aggregate variables to a very persistent rise in domestic productivity growth. Over the longer horizon along the adjustment path, the consumption-output ratio remains below its steady state, while hours worked remains above its steady state. 


\section{DATA PLOTS: TECHNOLOGY GROWTH AND HOURS}

\section{DATA PLOTS: TAX WEDGES}

SCATTERPLOTS: CORRELATIONS BETWEEN TECHNOLOGICAL GROWTH AND HOURS
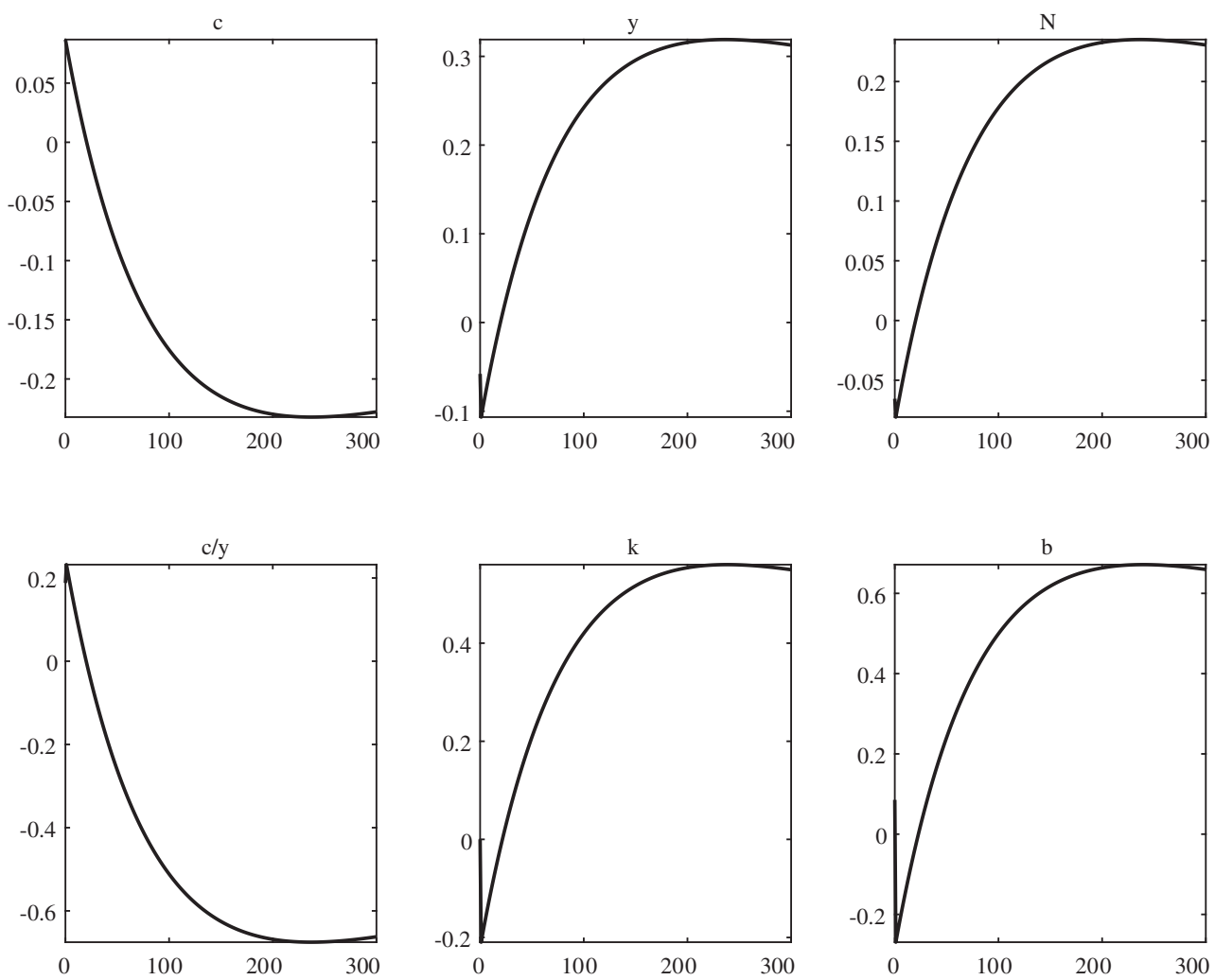

FIGURE A1. Impulse responses to a $1 \%$ increase in the productivity growth shock. 

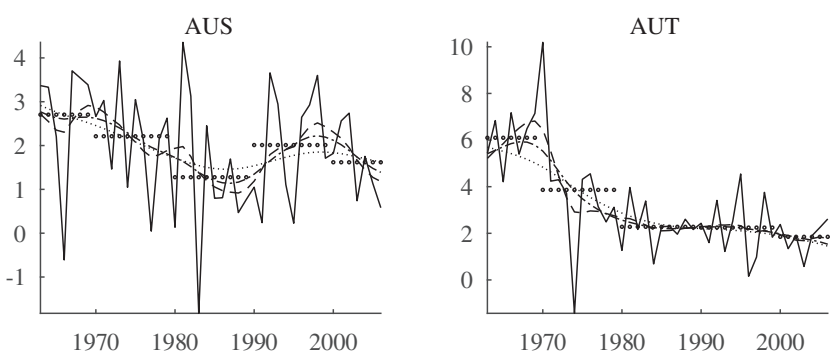

BEL

CAN

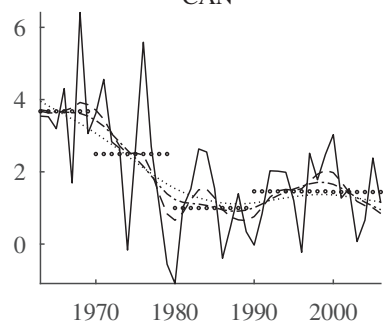

FIN
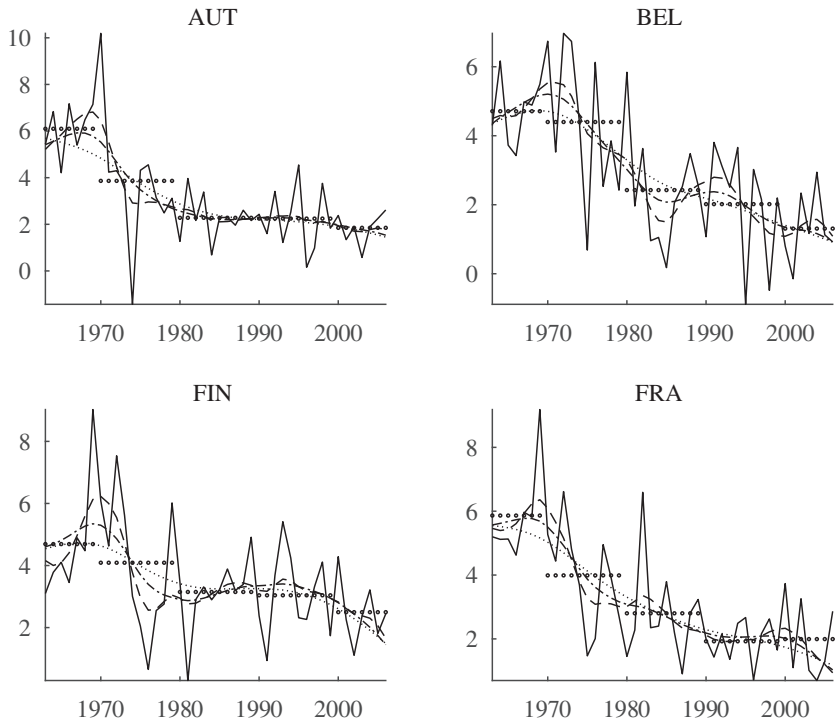

GER

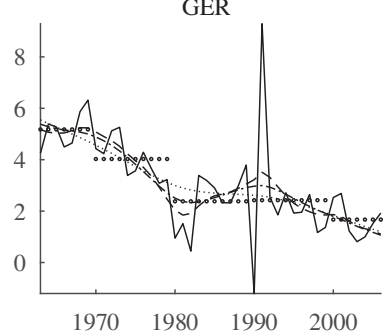

ITA
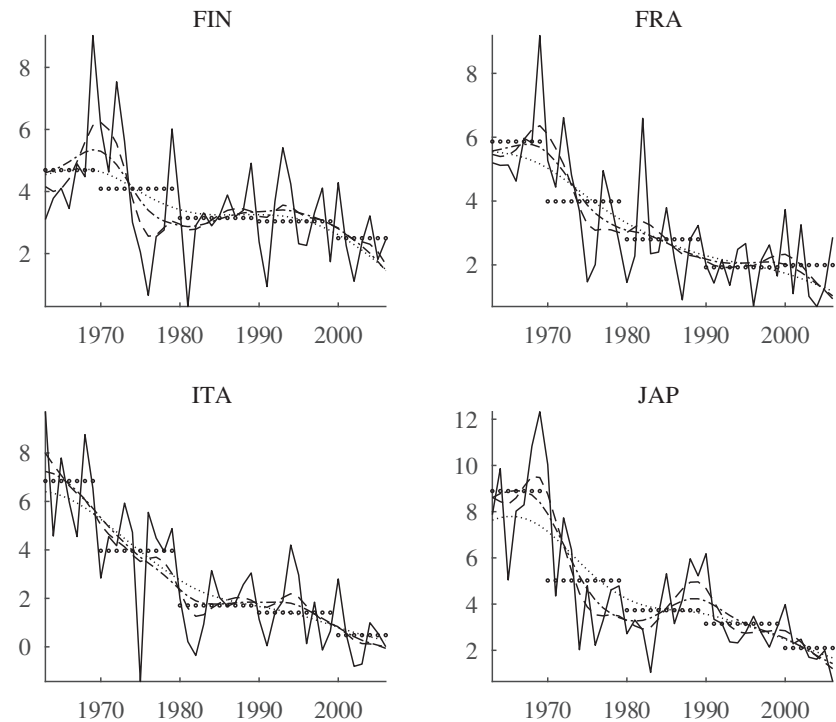

NLD

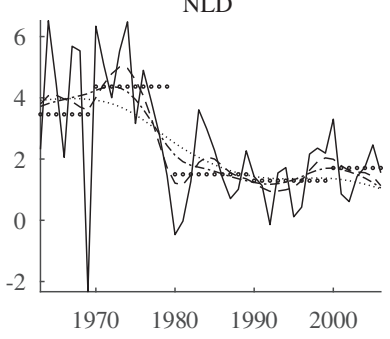

SPA
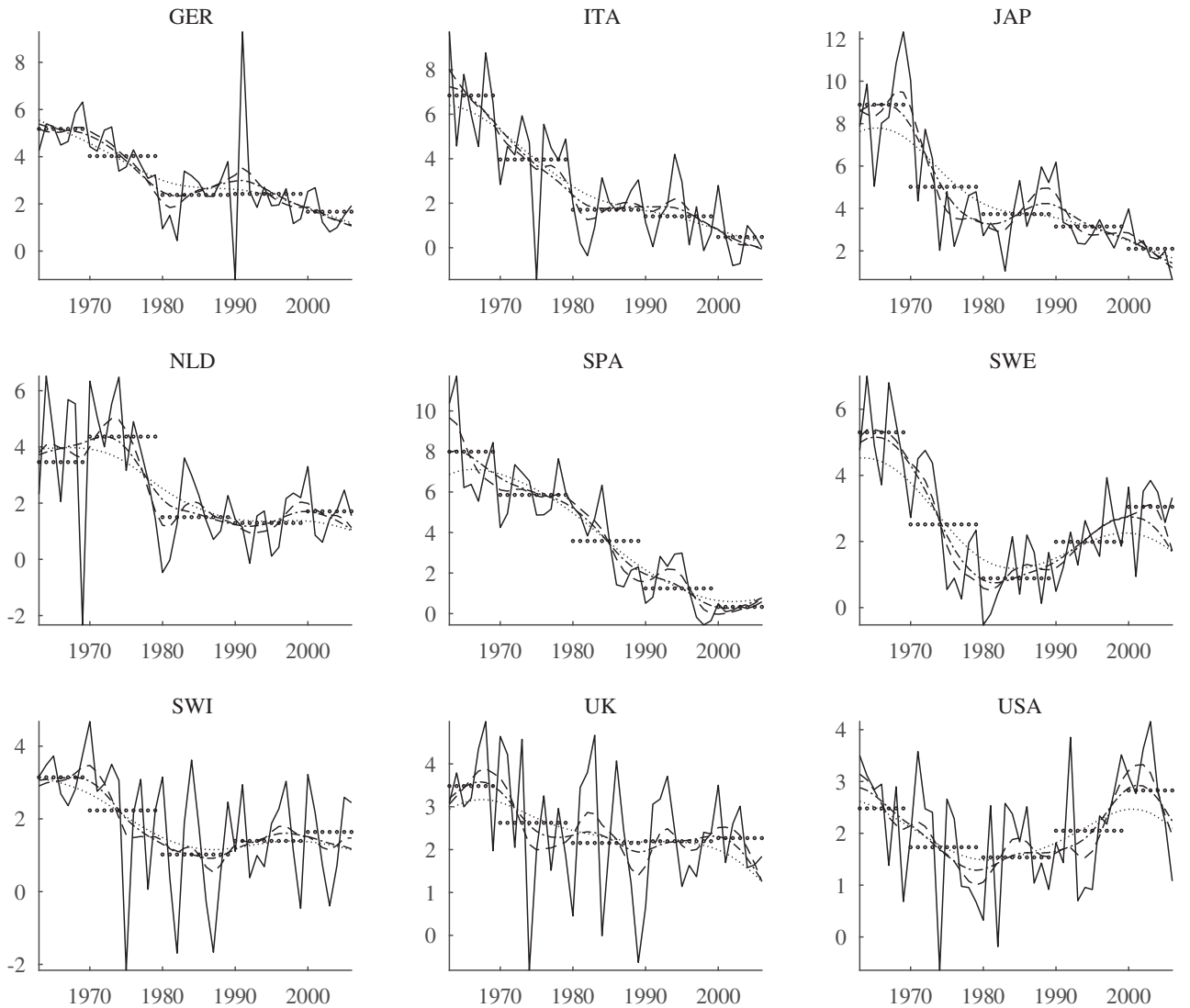

FIGURE A2. Labour productivity growth. Notes: Solid: data. Dashed: HP 6.25. Dashed-dotted: HP 62.5. Dotted: HP 625. Circles: decade averages. 

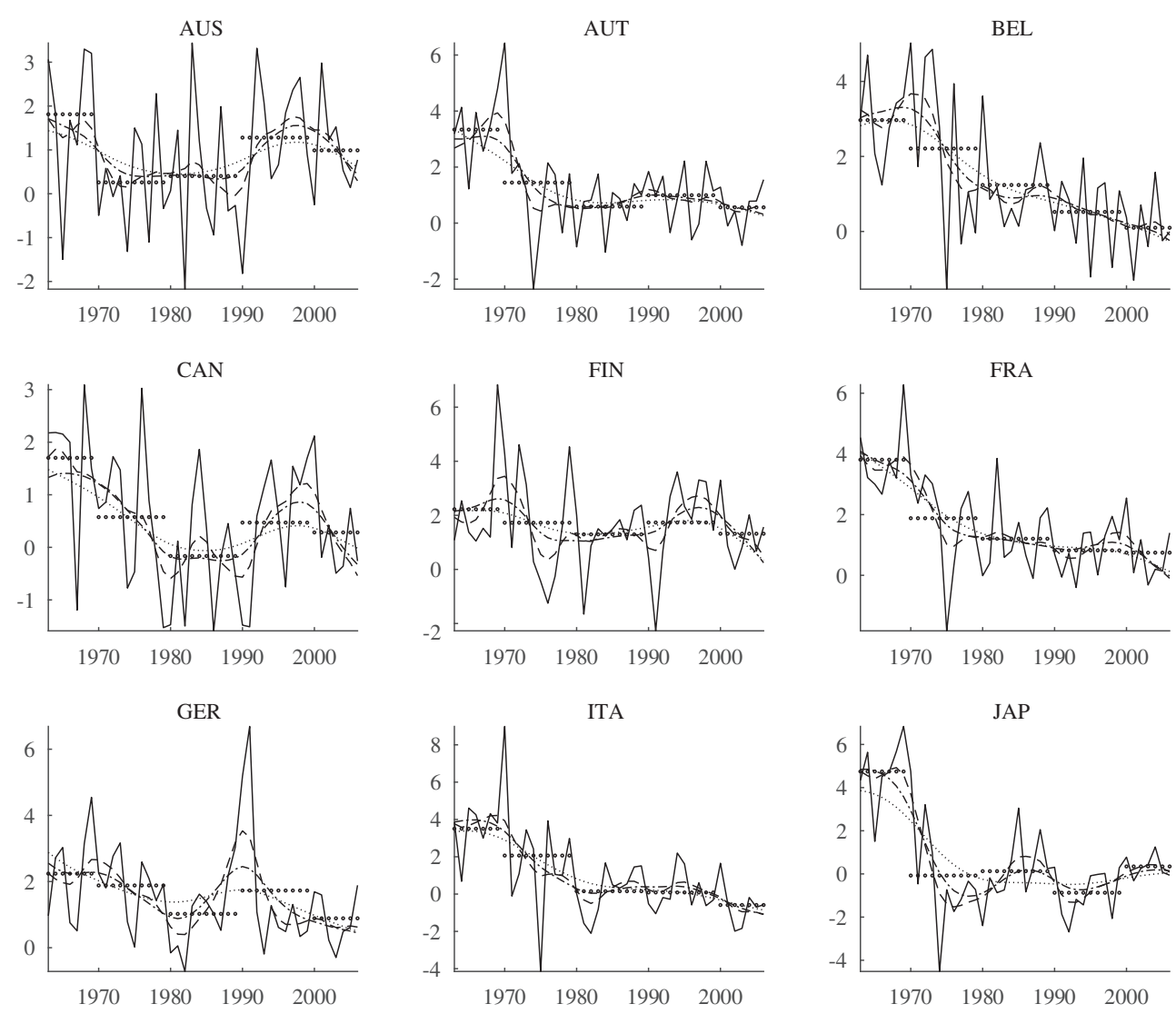

ITA
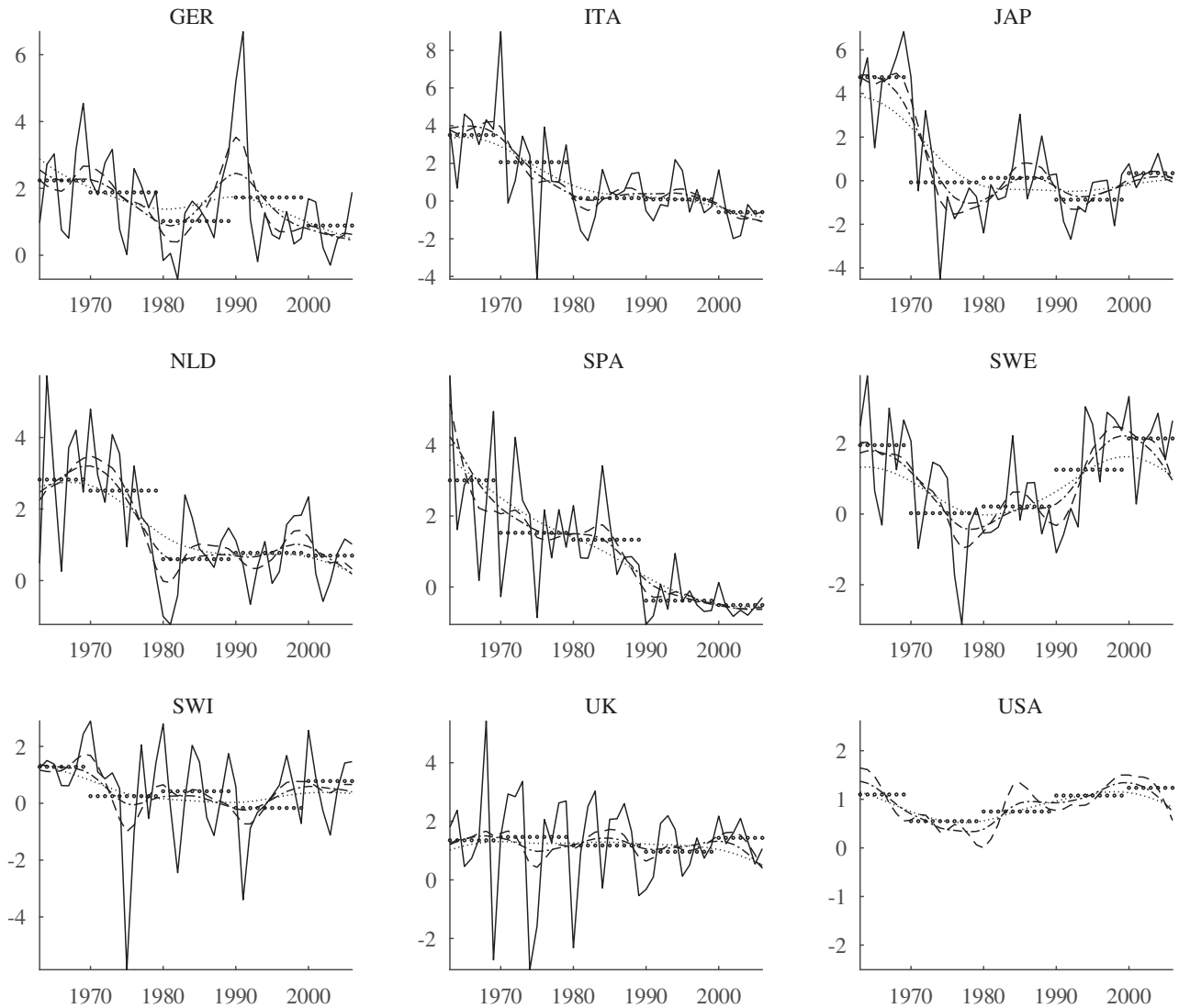

FIGURE A3. TFP growth. Notes: Solid: data. Dashed: HP 6.25. Dashed-dotted: HP 62.5. Dotted: HP 625. Circles: decade averages. 

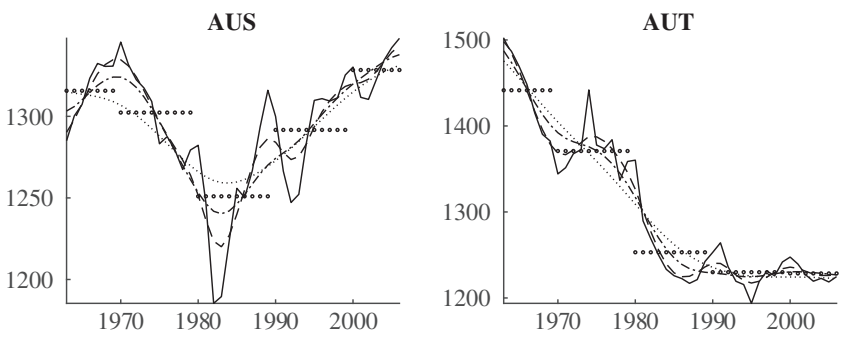

CAN
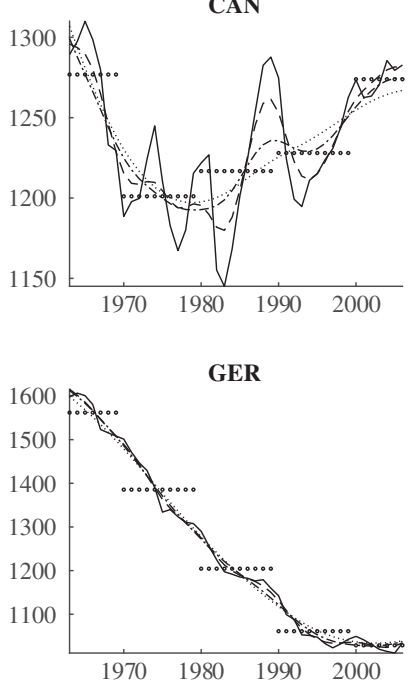

NLD

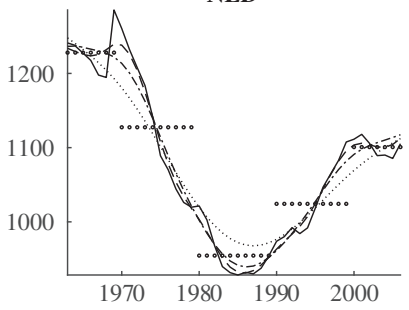

SWI

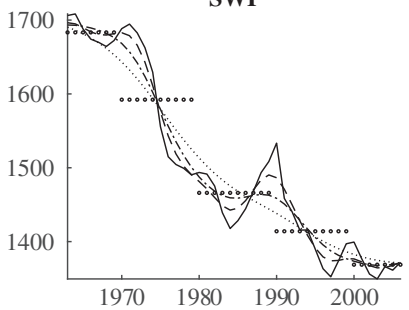

FIN

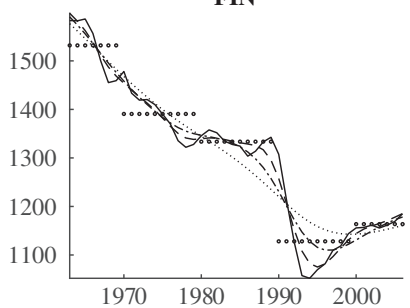

ITA

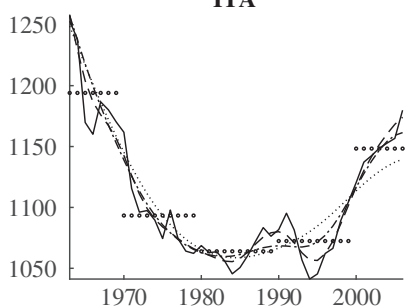

SPA

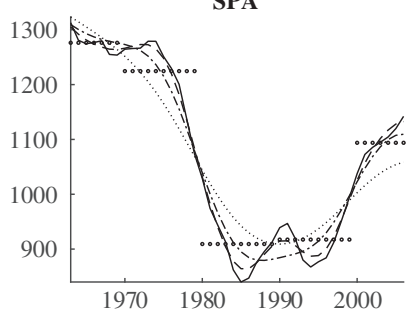

UK

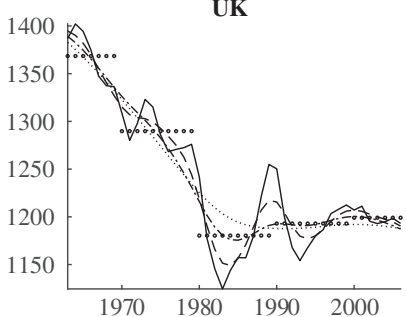

BEL

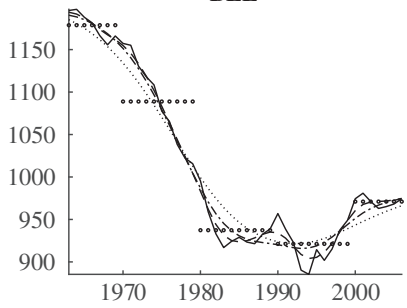

FRA

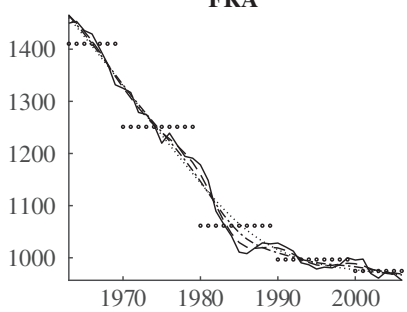

JAP

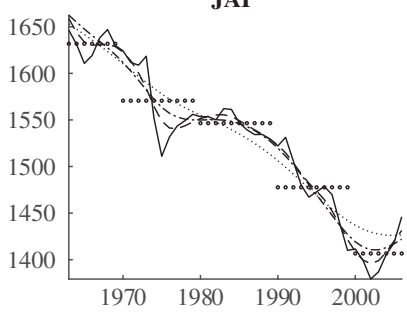

SWE

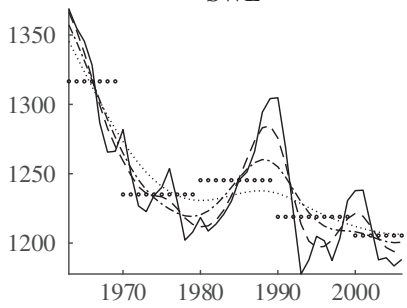

USA

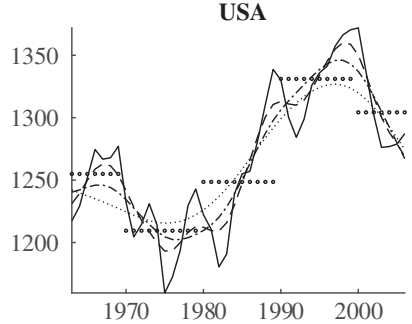

FIGURE A4. Hours. Notes: Solid: data. Dashed: HP 6.25. Dashed-dotted: HP 62.5. Dotted: HP 625. Circles: decade averages. 

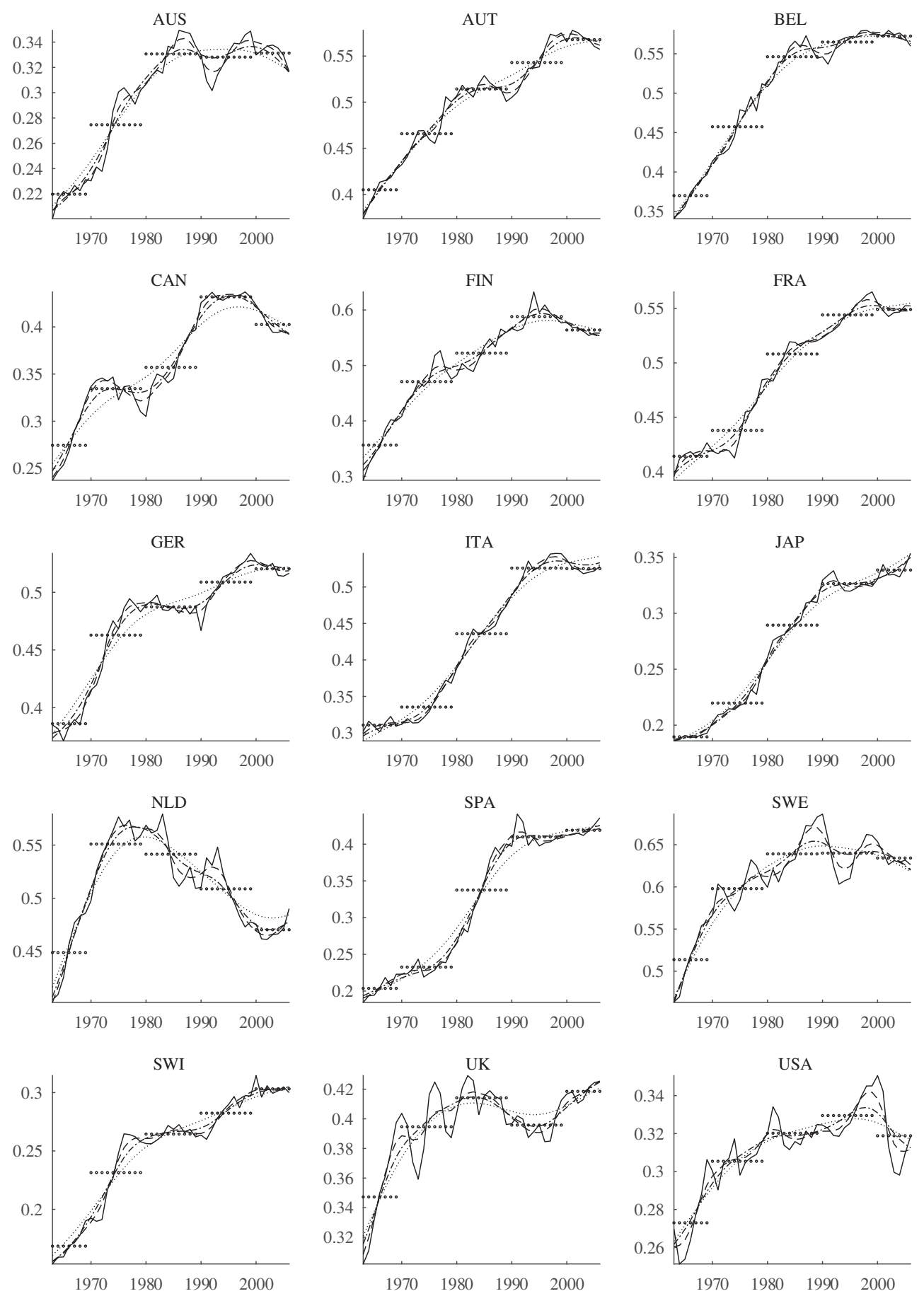

Figure A5. Tax wedge $\tau^{h}$. Notes: Solid: data. Dashed: HP 6.25. Dashed-dotted: HP 62.5. Dotted: HP 625. Circles: decade averages. 

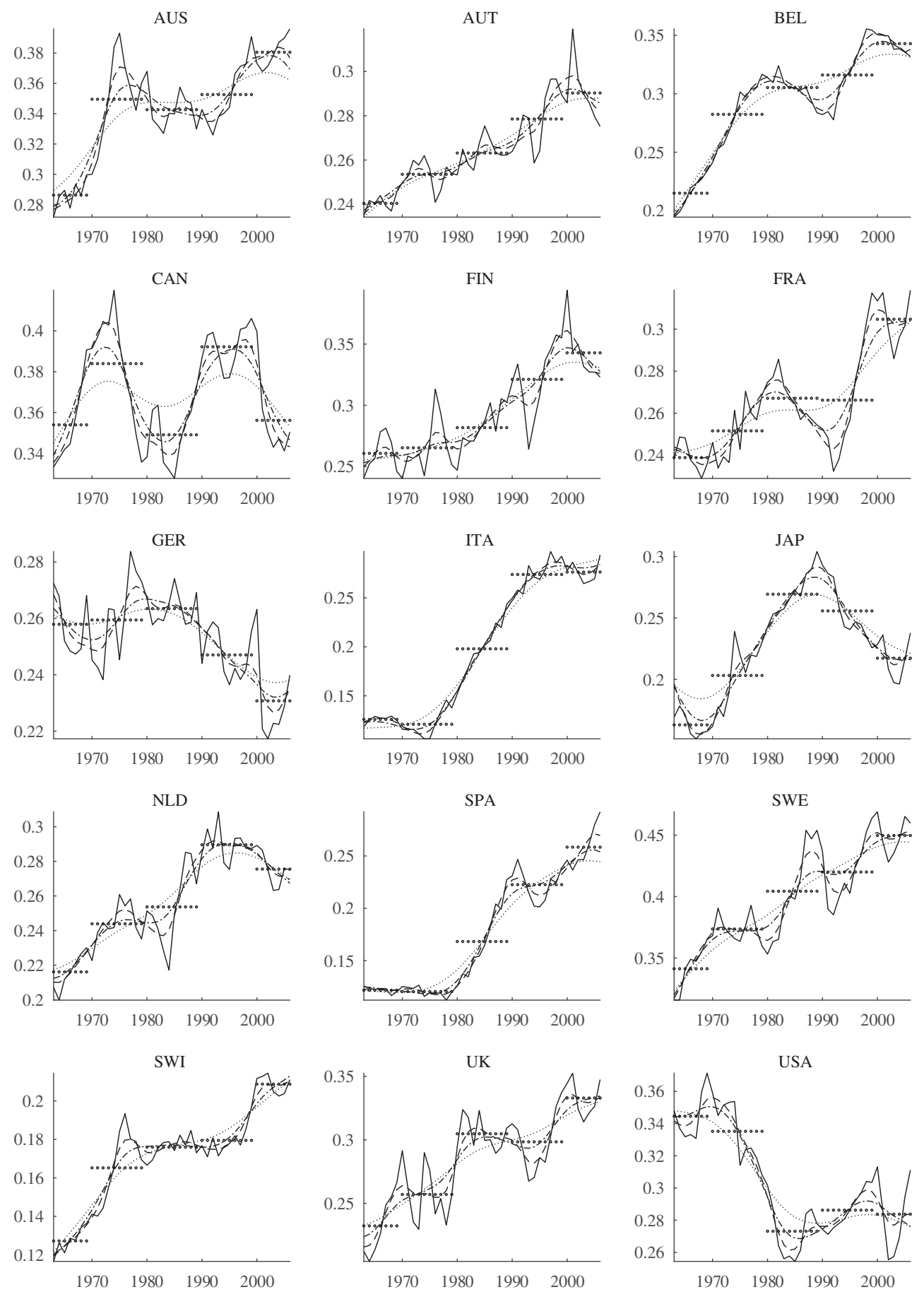

Figure A6. Tax wedge $\tau^{k}$. Notes: Solid: data. Dashed: HP 6.25. Dashed-dotted: HP 62.5. Dotted: HP 625. Circles: decade averages. 

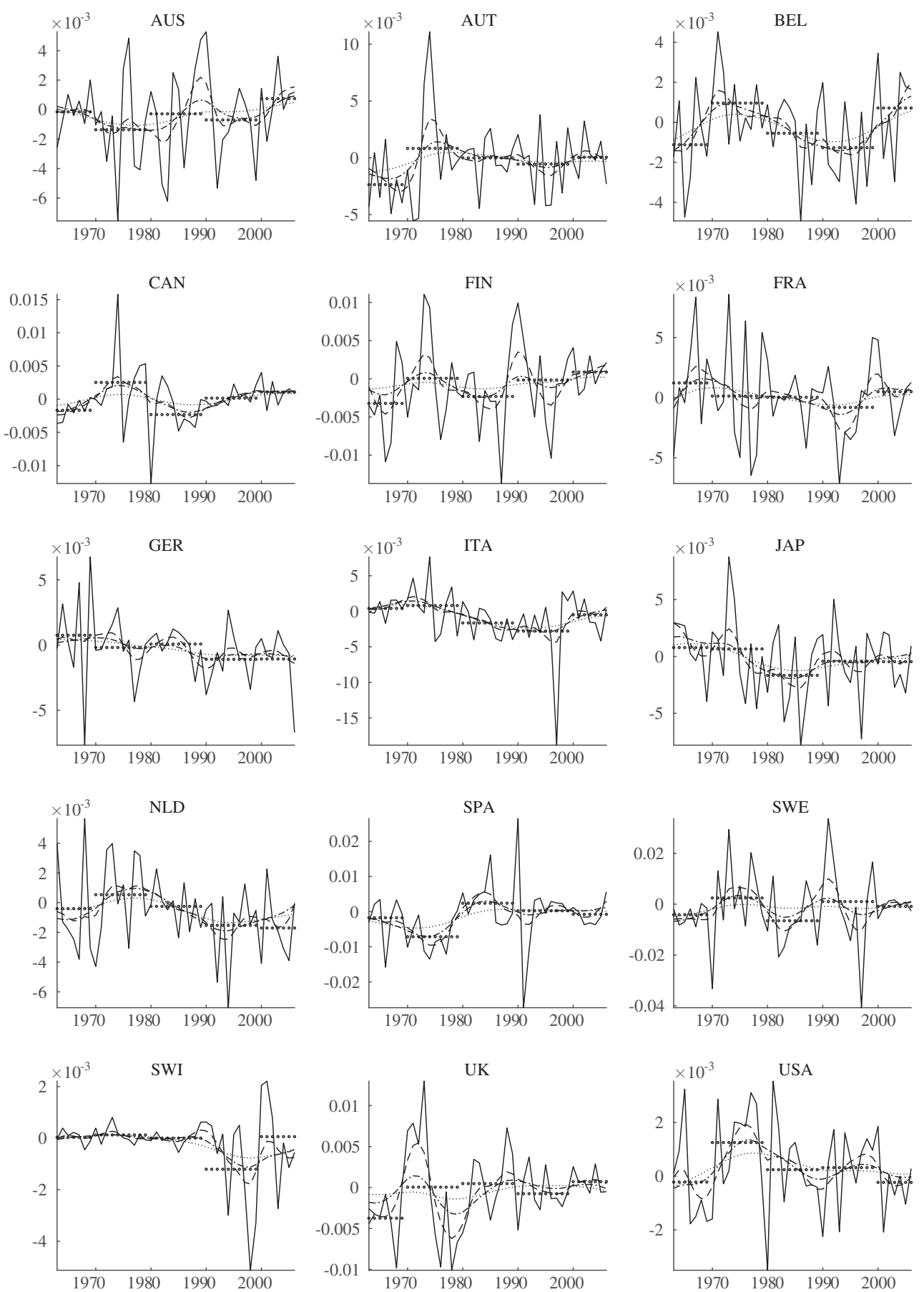

FIgURE A7. Tax wedge $\tau^{c x}$. Notes: Solid: data. Dashed: HP 6.25. Dashed-dotted: HP 62.5. Dotted: HP 625. Circles: decade averages. 

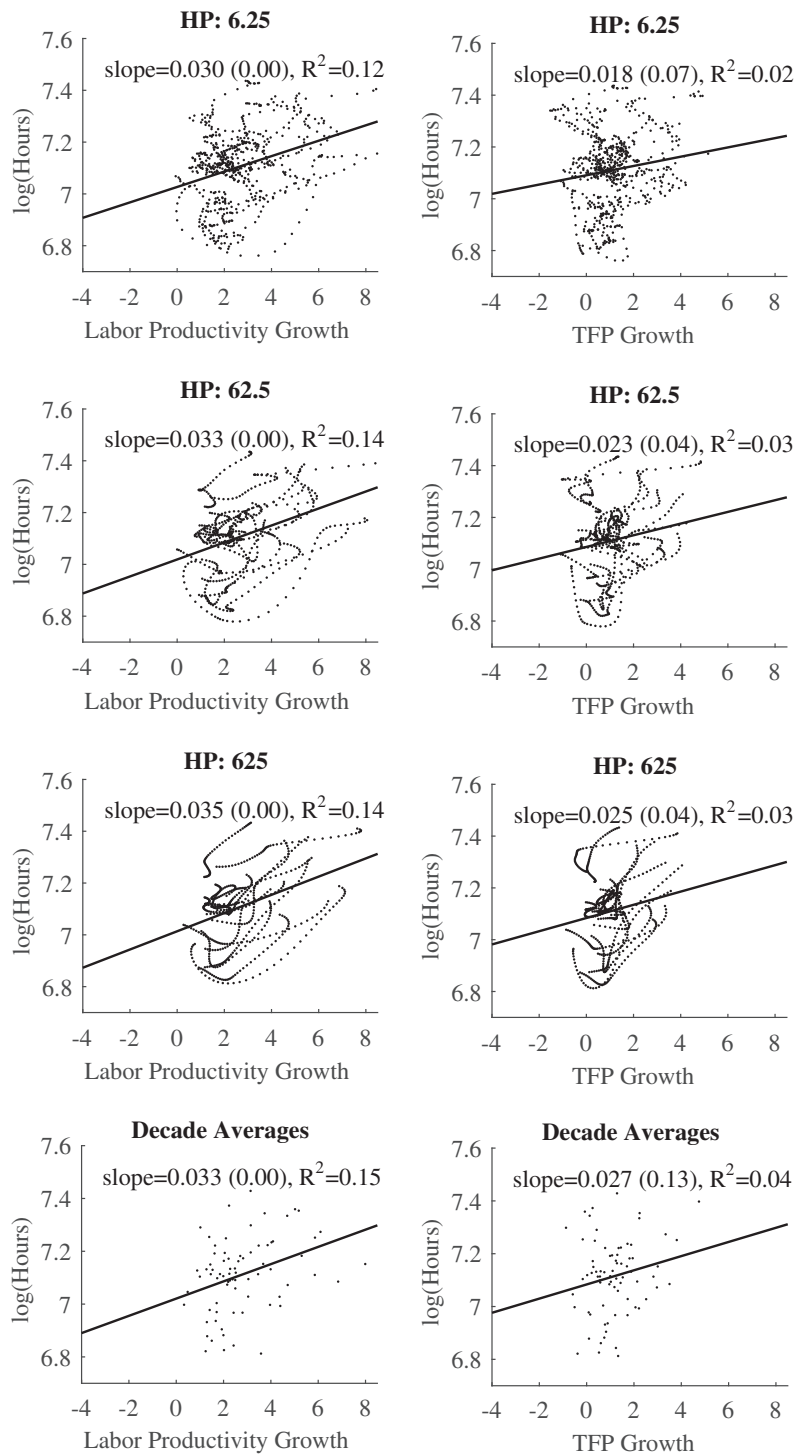

FIGURE A8. The empirical relationship between trend technology growth and hours. 

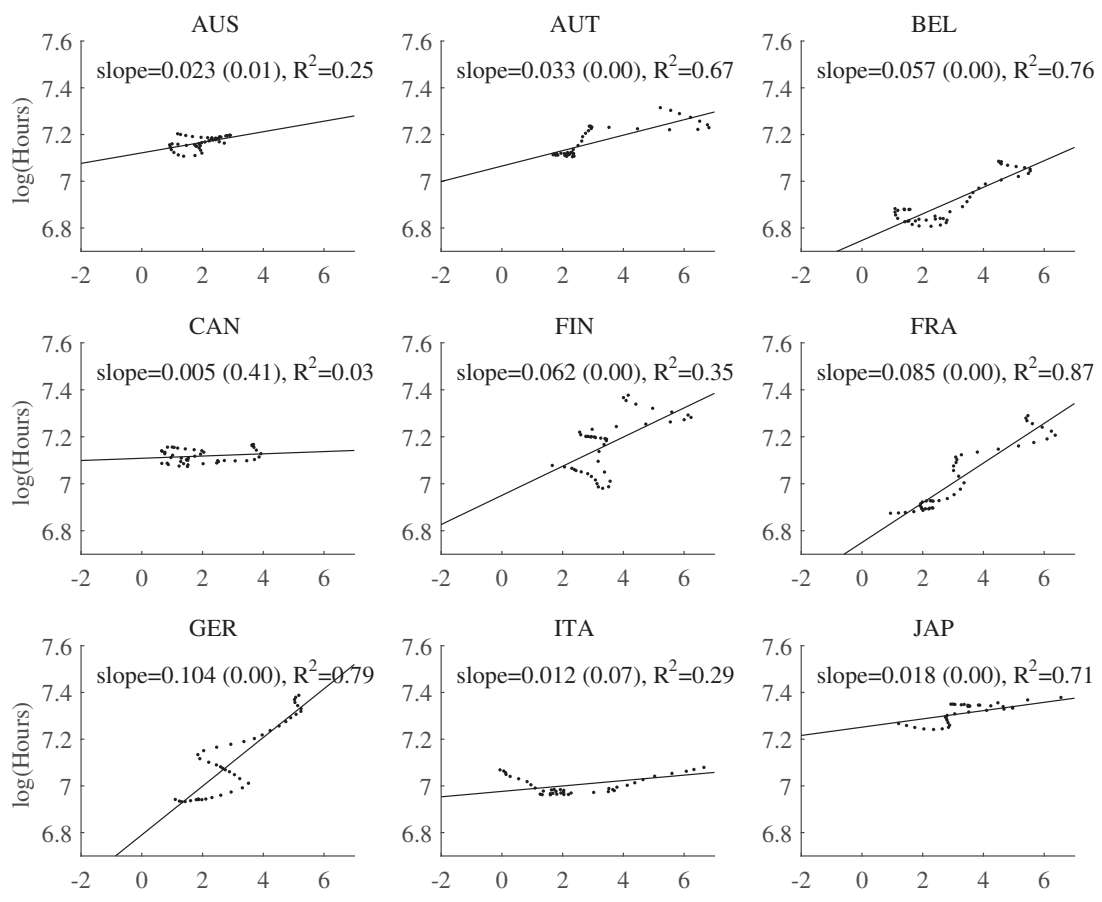

ITA

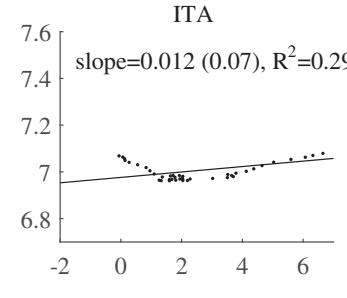

JAP
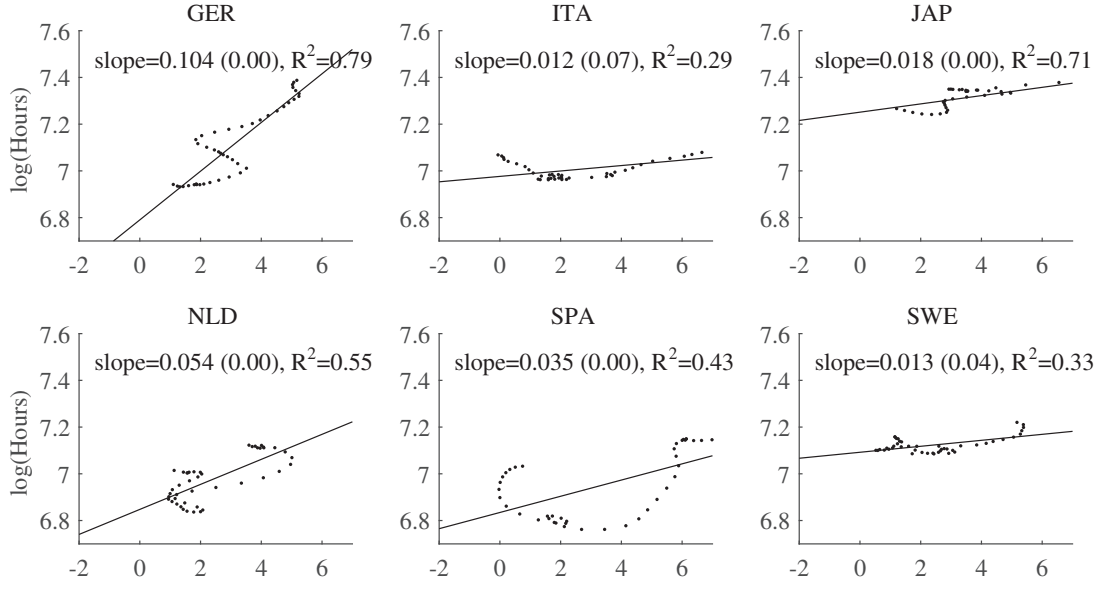

SPA

SWE
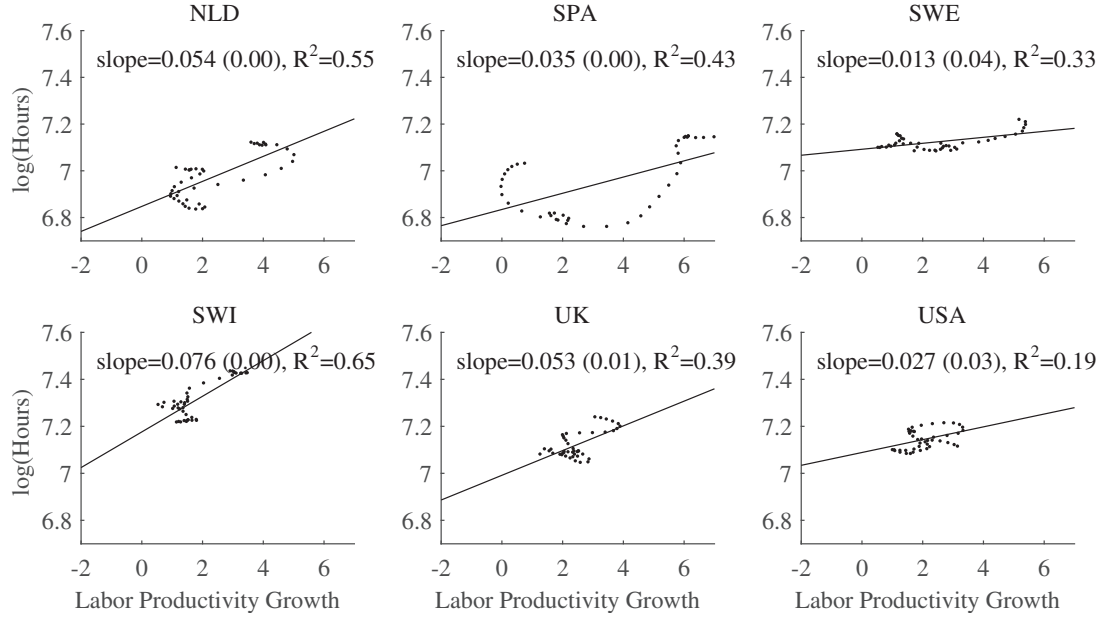

FIGURE A9. The link between labour productivity growth and hours in individual countries (HP 6.25). 

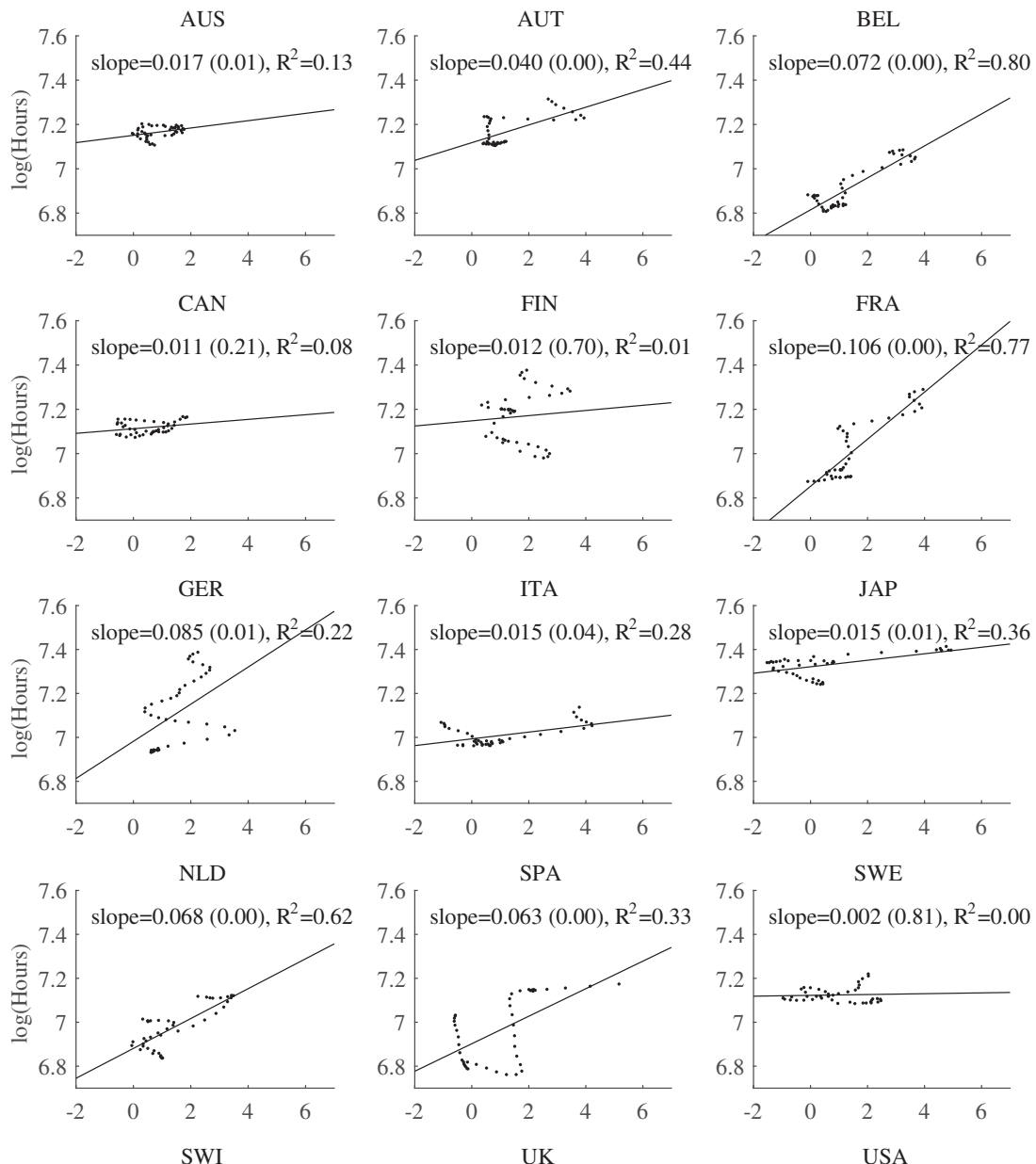

SWE
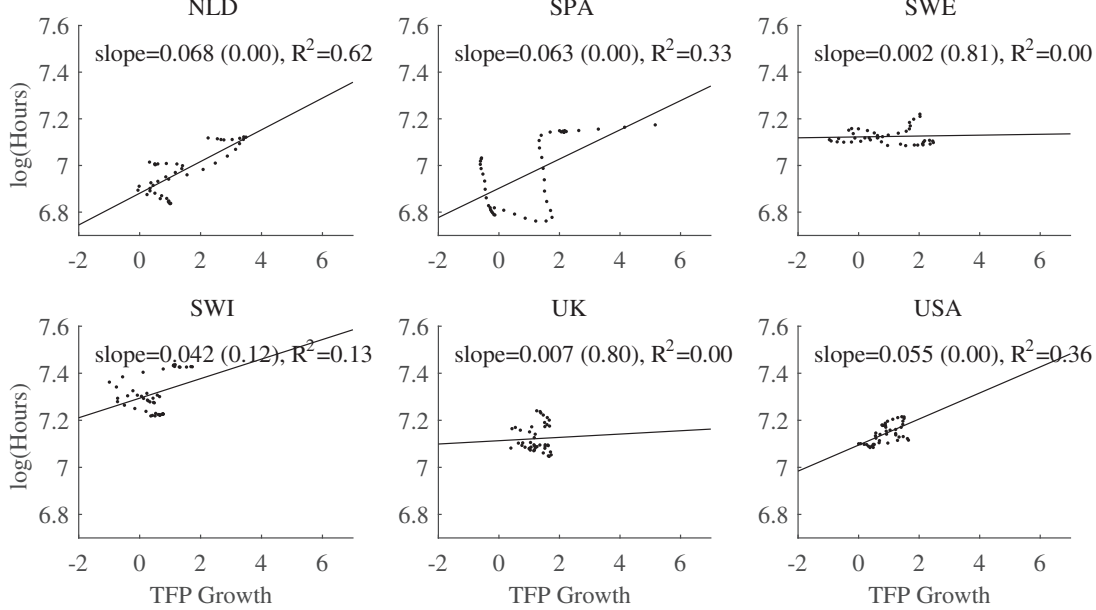

USA

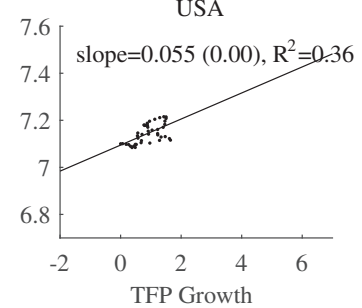

FIGURE A10. The empirical relationship between trend TFP growth and hours in individual countries (detrending: HP 6.25). 

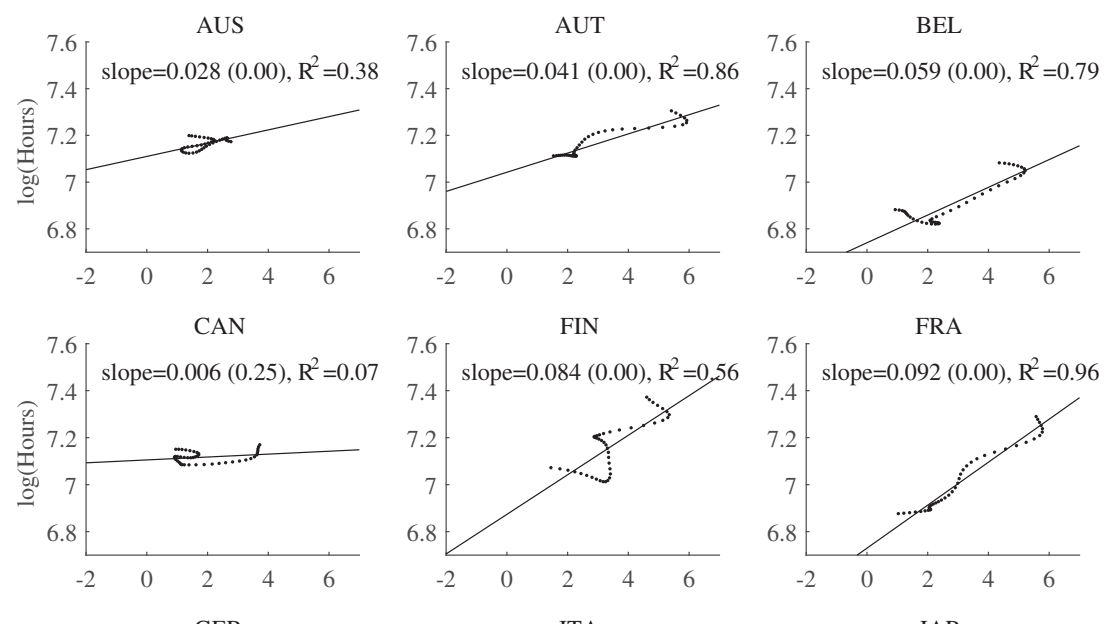

FRA
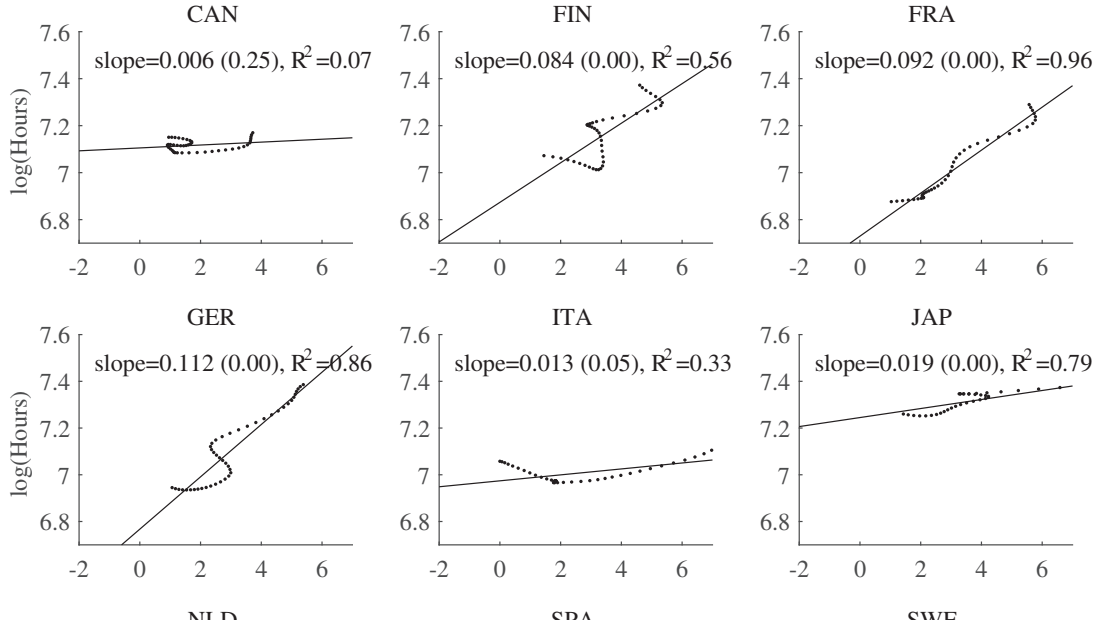

JAP
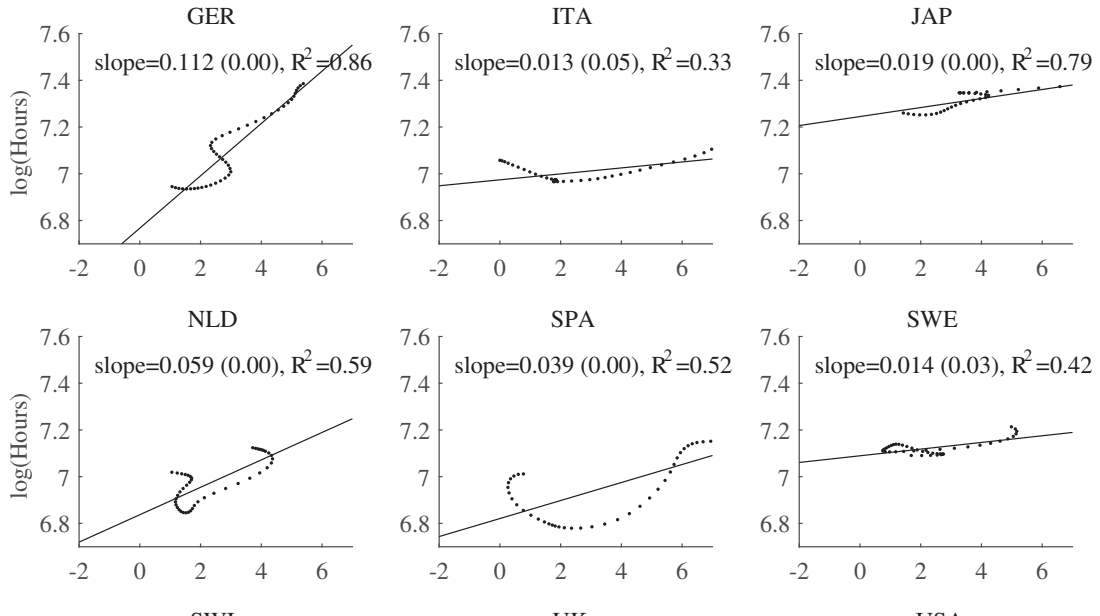

SPA

SWE
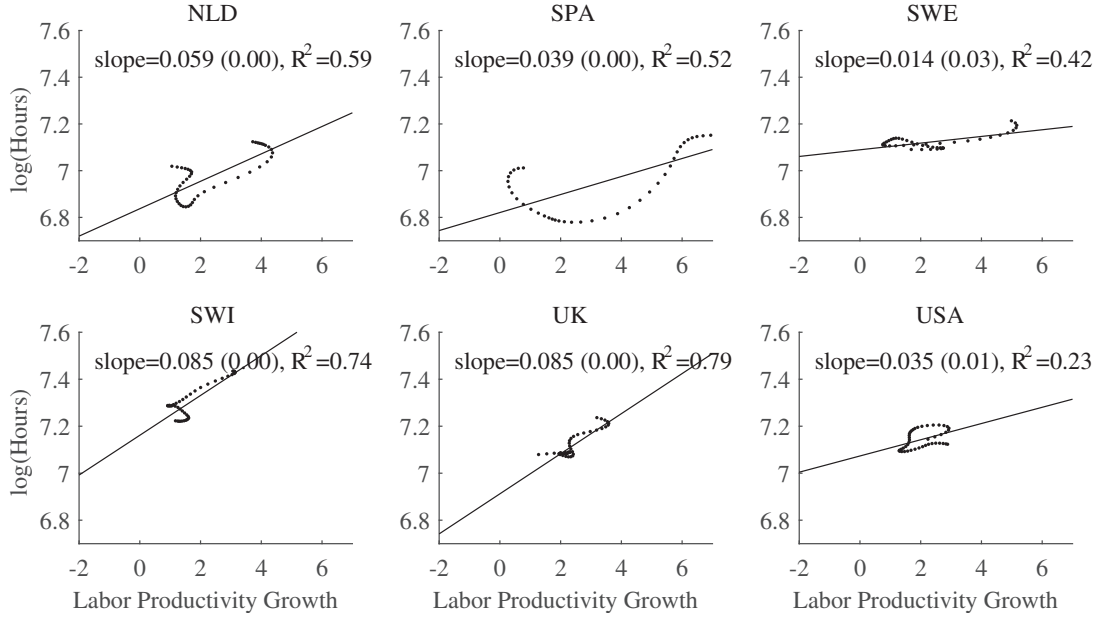

USA

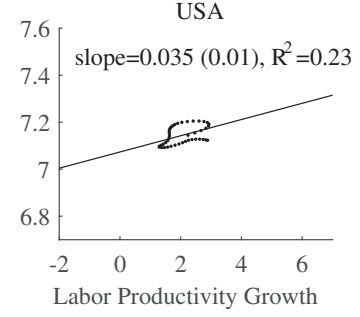

FIGURE A11. The empirical relationship between trend labour productivity growth and hours in individual countries (detrending: HP 62.5). 

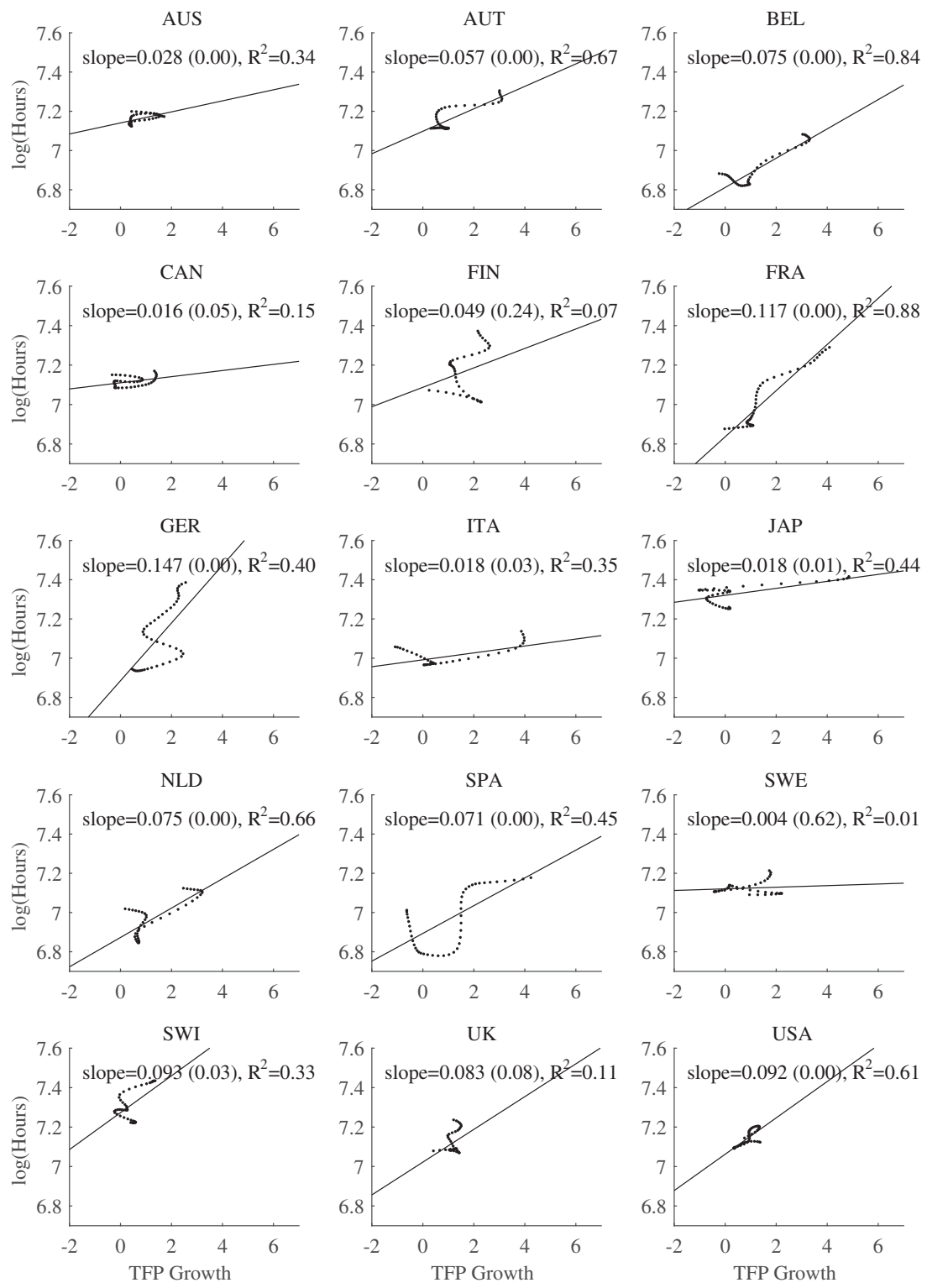

FIGURE A12. The empirical relationship between trend TFP growth and hours in individual countries (detrending: HP 62.5). 

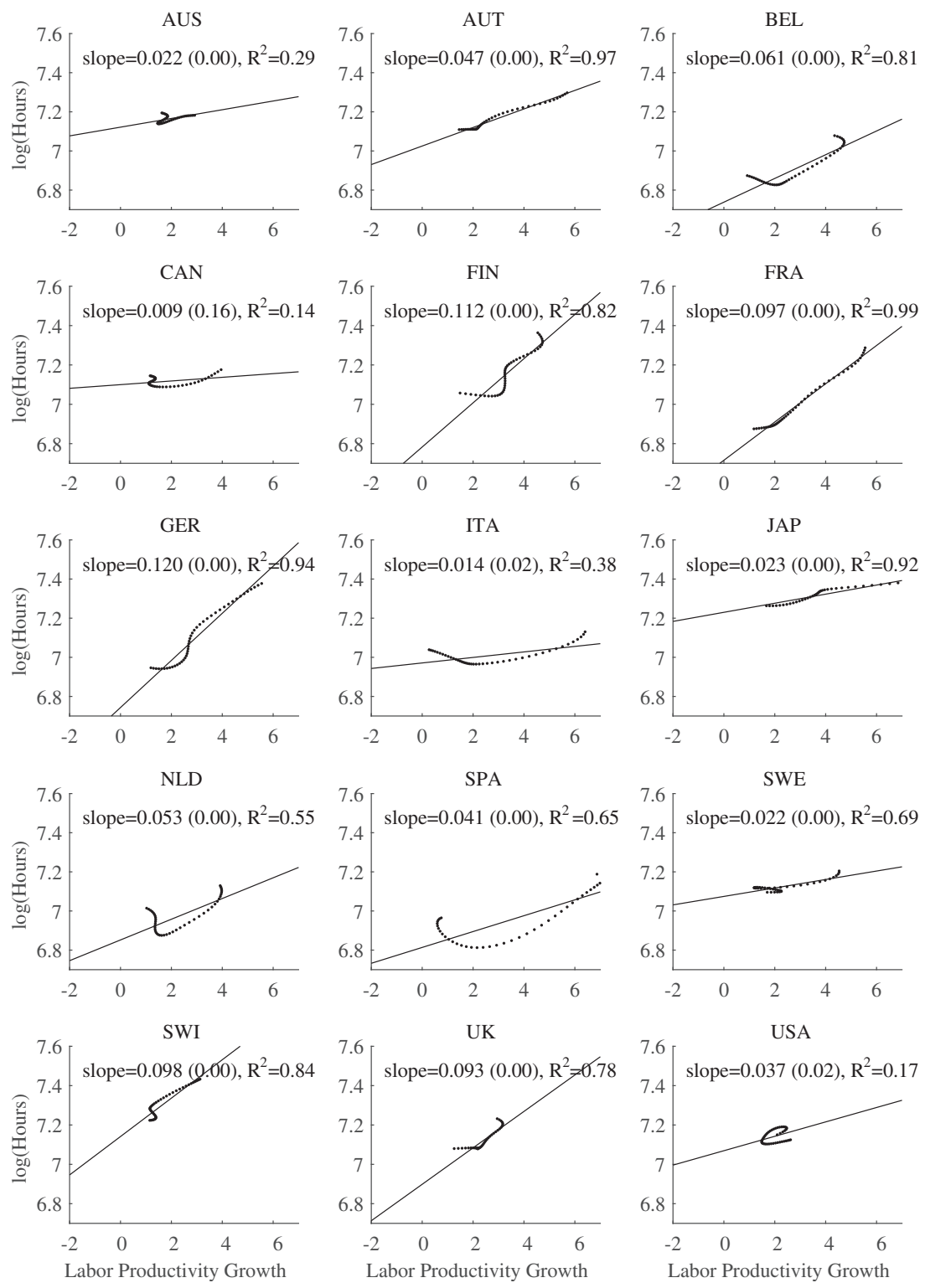

FIGURE A13. The empirical relationship between trend labour productivity growth and hours in individual countries (detrending: HP 625). 

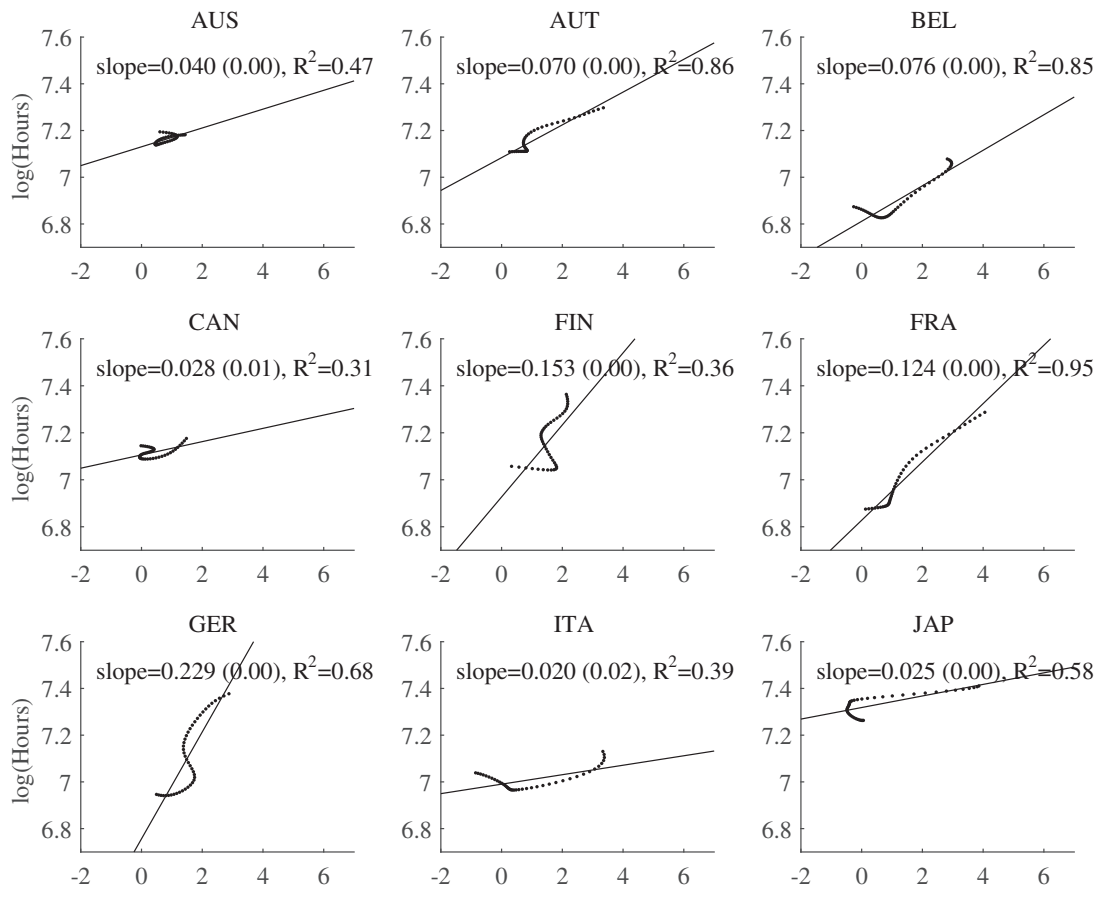

JAP
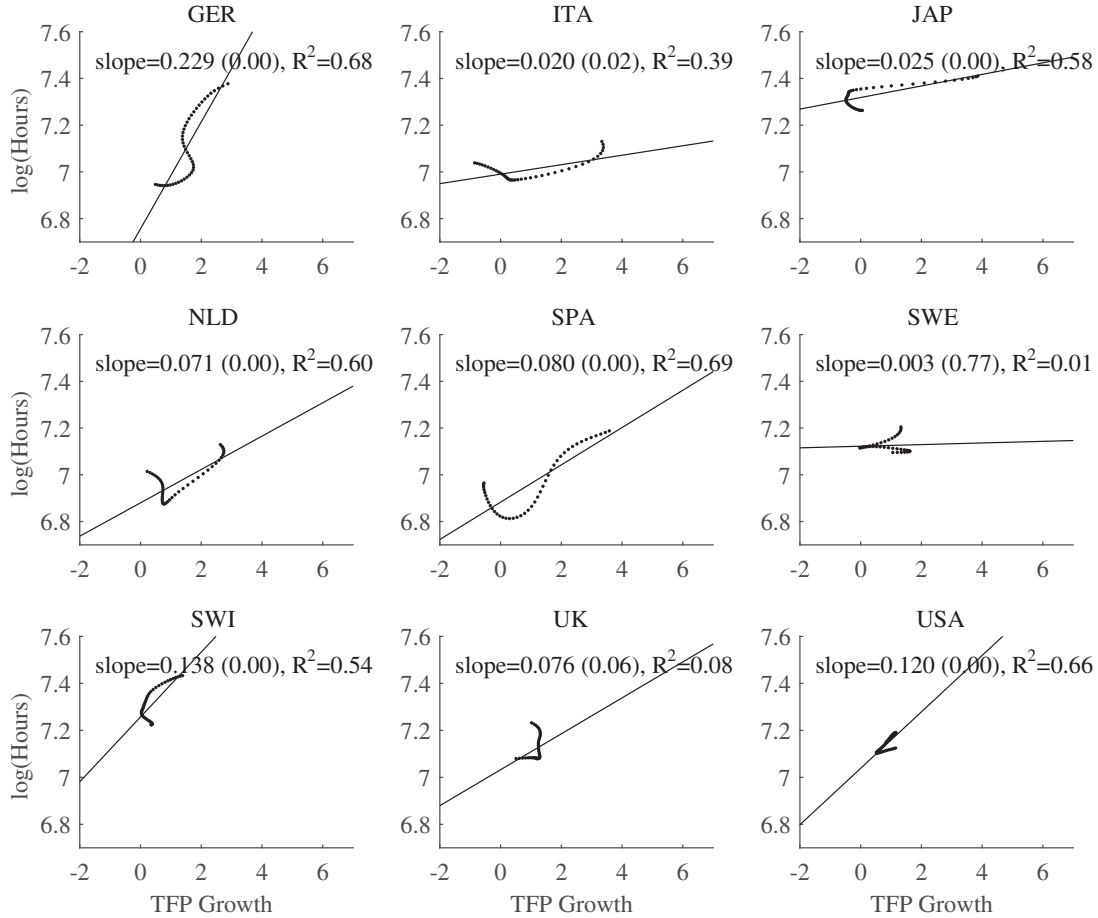

FIGURE A14. The empirical relationship between trend TFP growth and hours in individual countries (detrending: HP 625). 

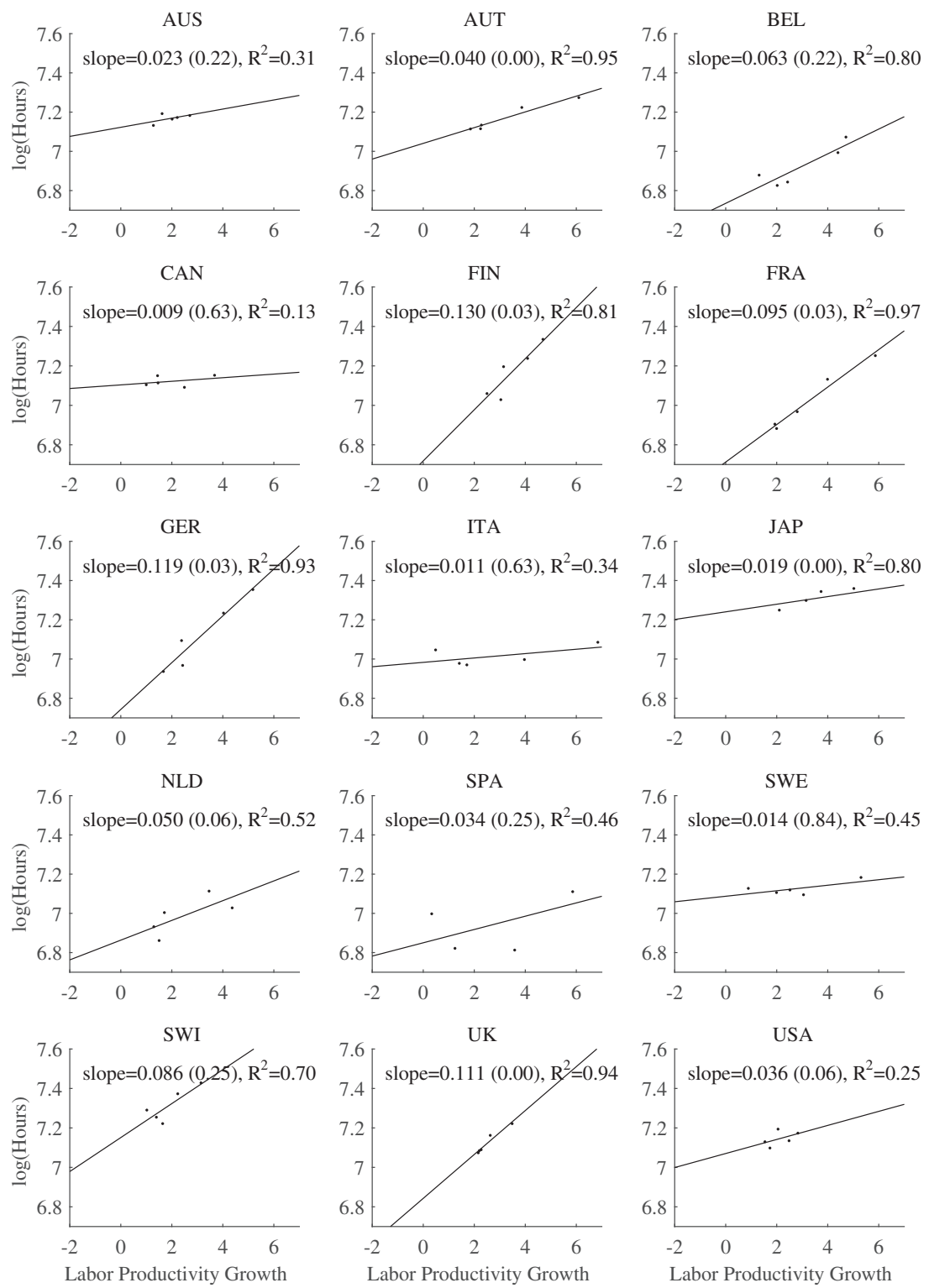

FIGURE A15. The empirical relationship between trend labour productivity growth and hours in individual countries (decade averages). 

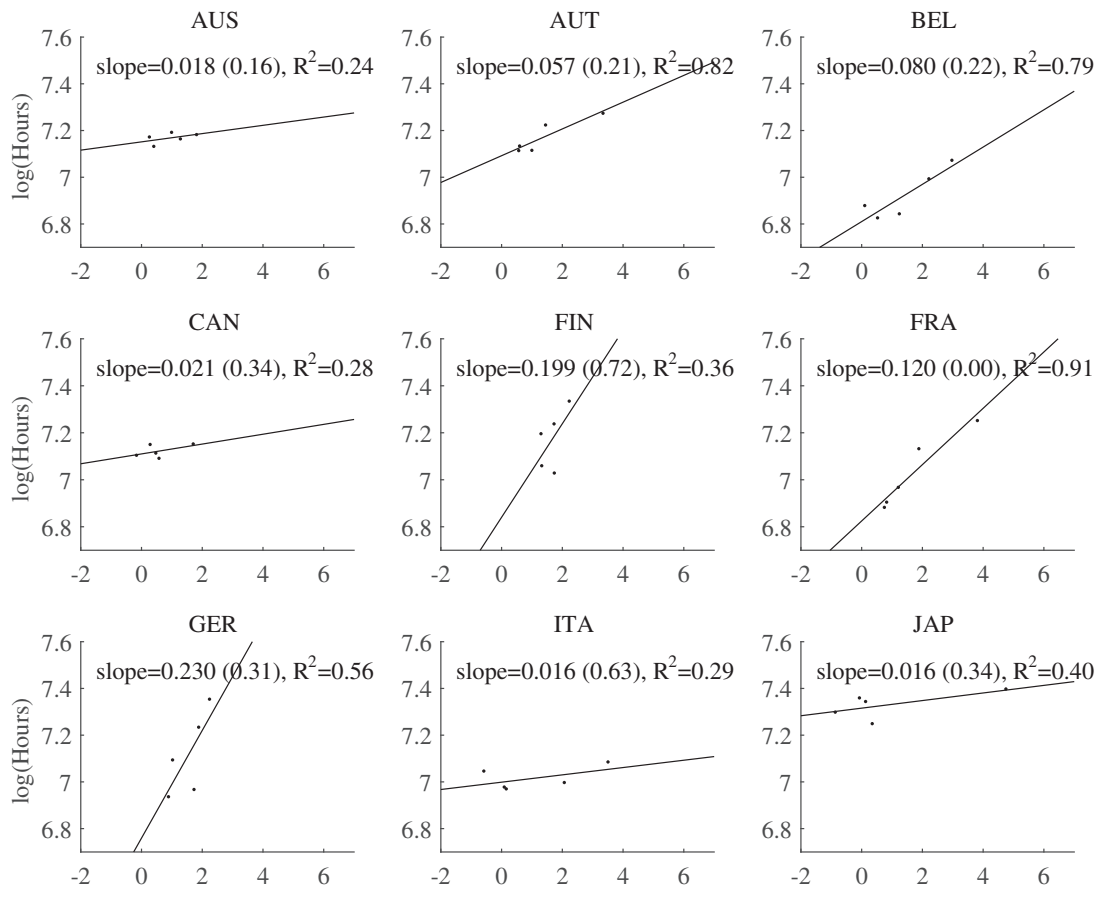

JAP
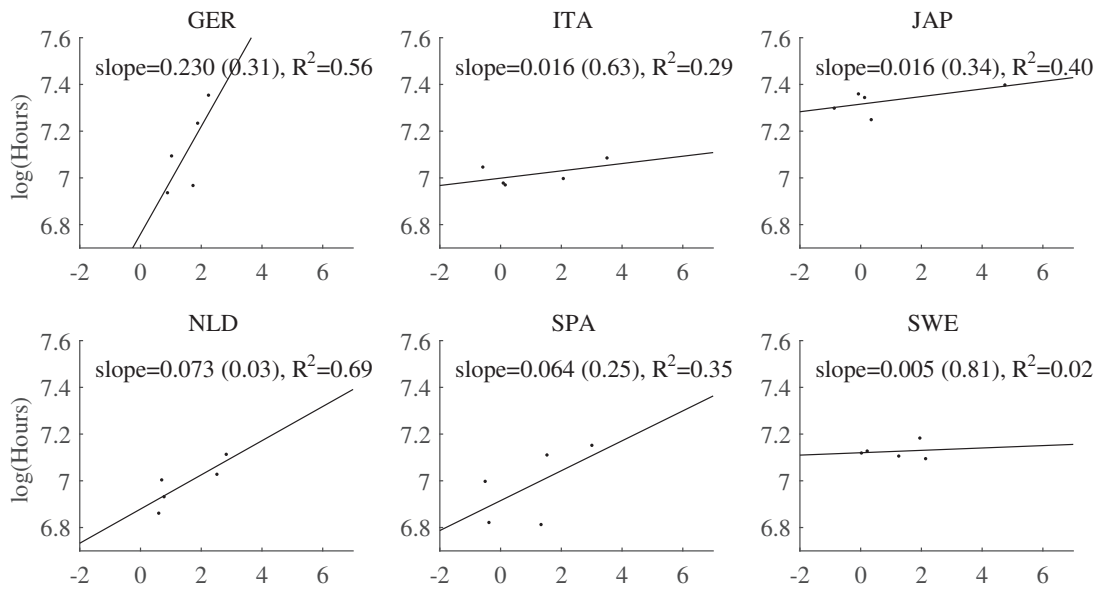

SPA

SWE
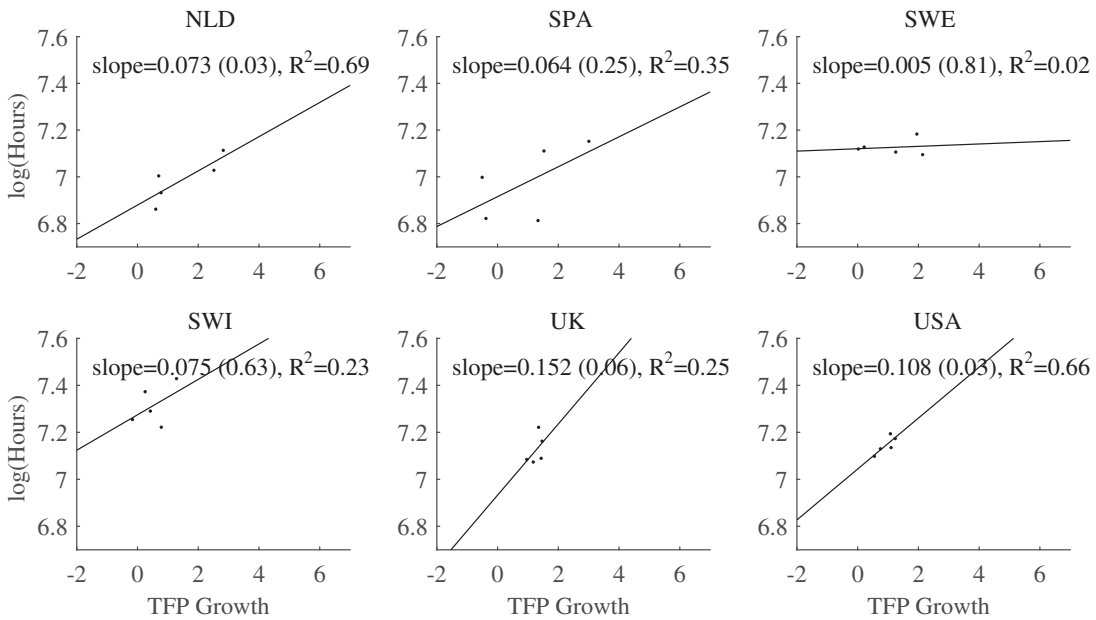

FIGURE A16. The empirical relationship between trend TFP growth and hours in individual countries (decade averages). 